Supplementary Information for

\title{
Highly Active Gas Phase Organometallic Catalysis Supported Within Metal-organic Framework Pores
}

\author{
Ricardo A. Peraltaa, Michael T. Huxleya, Jack D. Evans ${ }^{b}$, Haijie Cao ${ }^{c}$, Maoxia He ${ }^{d}$, Xiu Song \\ Zhao $^{\mathrm{c}, \mathrm{e}}$, Stefano Agnolif , Christopher J. Sumby ${ }^{\text {a* }}$ and Christian J. Doonan ${ }^{\text {** }}$ \\ a Centre for Advanced Nanomaterials and Department of Chemistry, The University of Adelaide, North Terrace, Adelaide, \\ SA 5000, Australia. Email: christopher.sumby@adelaide.edu.au (CJS); christian.doonan@adelaide.edu.au (CJD) \\ b Department of Inorganic Chemistry, Technische Universität Dresden, Bergstraße 66, 01062 Dresden, Germany \\ ${ }^{c}$ Institute of Materials for Energy and Environment, College of Materials Science and Engineering, Qingdao University, \\ Qingdao, 266071, PR China \\ d Environment Research Institute, Shandong University, Qingdao, 266237, PR China \\ e School of Chemical Engineering, The University of Queensland, St Lucia, Brisbane, 4072. Australia \\ ${ }^{\mathrm{f}}$ Dipartimento di Scienze Chimiche, Università di Padova, Via Marzolo 1, 35131 Padova, Italy
}




\section{Index}

SI 1.0 Energy Dispersive X-ray (EDX) Analysis

SI 2.0 High Resolution Transmission Electron Microscopy (HR-TEM), Selected Area Electron Diffraction (SAED) and EDX analysis for 1-NBD-Cl after the hydrogenation

SI 3.0 Transmission Electron Microscopy (TEM) data and particle size analysis for 1 -NBD-Cl after the hydrogenation

SI 4.0 Powder X-ray Diffraction (PXRD) plots

SI 5.0 Single Crystal X-ray Crystallography

5.1 General procedures

5.2 Specific Refinement Details

5.3 Thermal ellipsoid plots for all structures at the $50 \%$ probability level

5.4 $\mathrm{F}_{\text {obs }}$ Electron Density Maps for all structures $\quad$ S23

5.5 Tables of X-ray crystallography data collection and refinement parameters $\quad$ S27

SI 6.0 Isotherm data $\quad$ S30

SI 7.0 Nuclear Magnetic Resonance (NMR) data $\quad$ S32

7.1 Time resolved NMR data for ethylene hydrogenation $\quad$ S32

7.2 Time resolved NMR data for butene isomerisation S33

7.3 Sample composition analysis using a $\mathrm{CO}$ probe in $\mathrm{CH}_{4} \quad \mathrm{~S} 34$

7.4 Analysis of 2-butene isomers generated under gas-phase catalysis $\quad$ S37

SI 8.0 Infrared (IR) spectroscopy $\quad$ S38

SI 9.0 High-pressure reaction vessel details $\quad$ S39

SI 10.0 X-ray Photoelectron Spectroscopy (XPS) Experiments S41

SI 11.0 Computational supplementary information $\quad$ S42

SI 12.0 References $\quad$ S49 


\section{SI 1.0 Energy Dispersive X-ray (EDX) Analysis}

Table S1: $\mathrm{Rh}(\mathrm{I})$ and associated anion occupancy determined via measurement of the $\mathrm{Mn}: \mathrm{Rh}$ ratio and the $\mathrm{Rh}: \mathrm{Cl}$ ratio using EDX analysis.

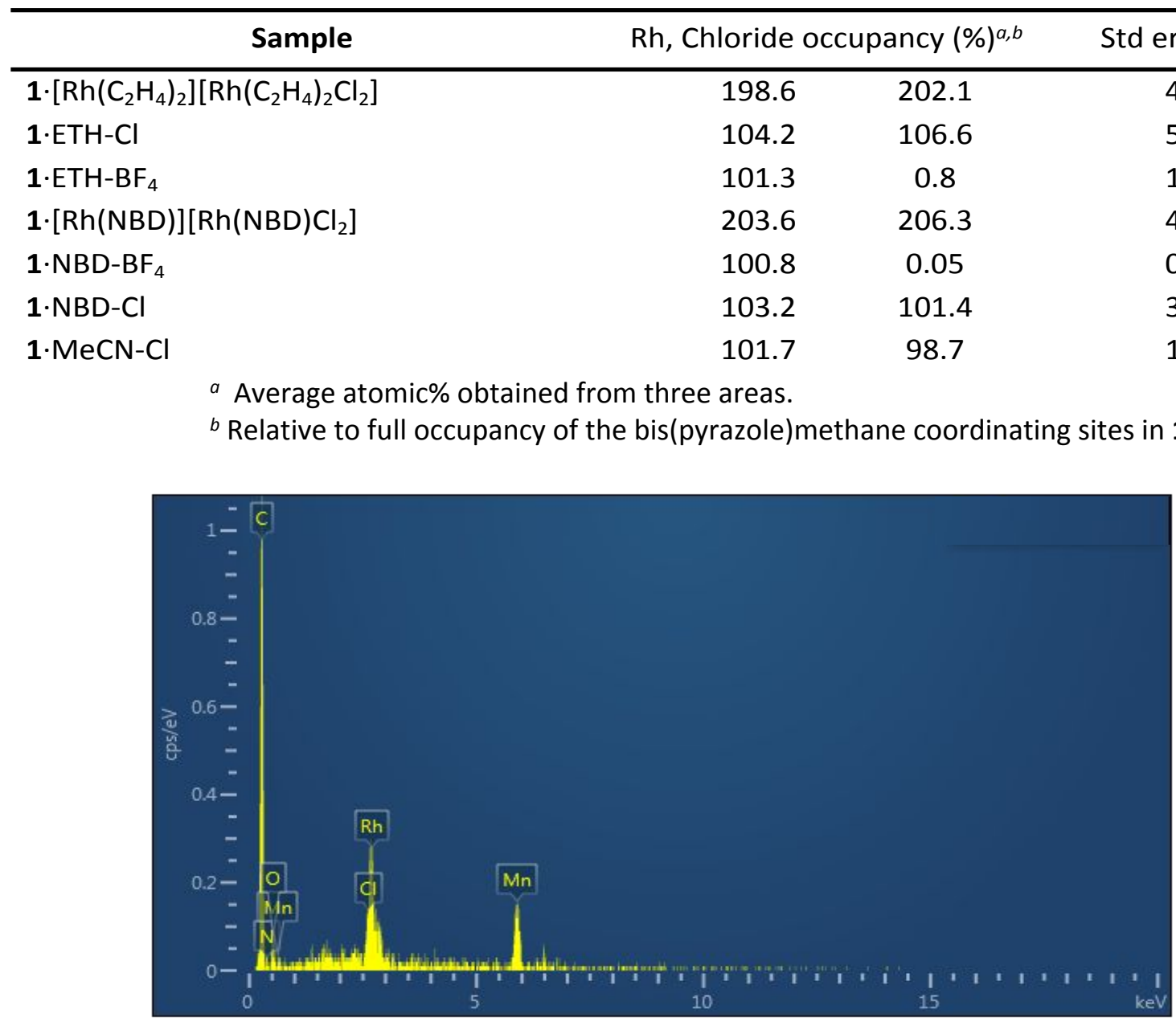

Figure SI 1.1: Representative raw EDX spectra for 1. $\left[\mathrm{Rh}\left(\mathrm{C}_{2} \mathrm{H}_{4}\right)_{2}\right]\left[\mathrm{Rh}\left(\mathrm{C}_{2} \mathrm{H}_{4}\right)_{2} \mathrm{Cl}_{2}\right]$. 

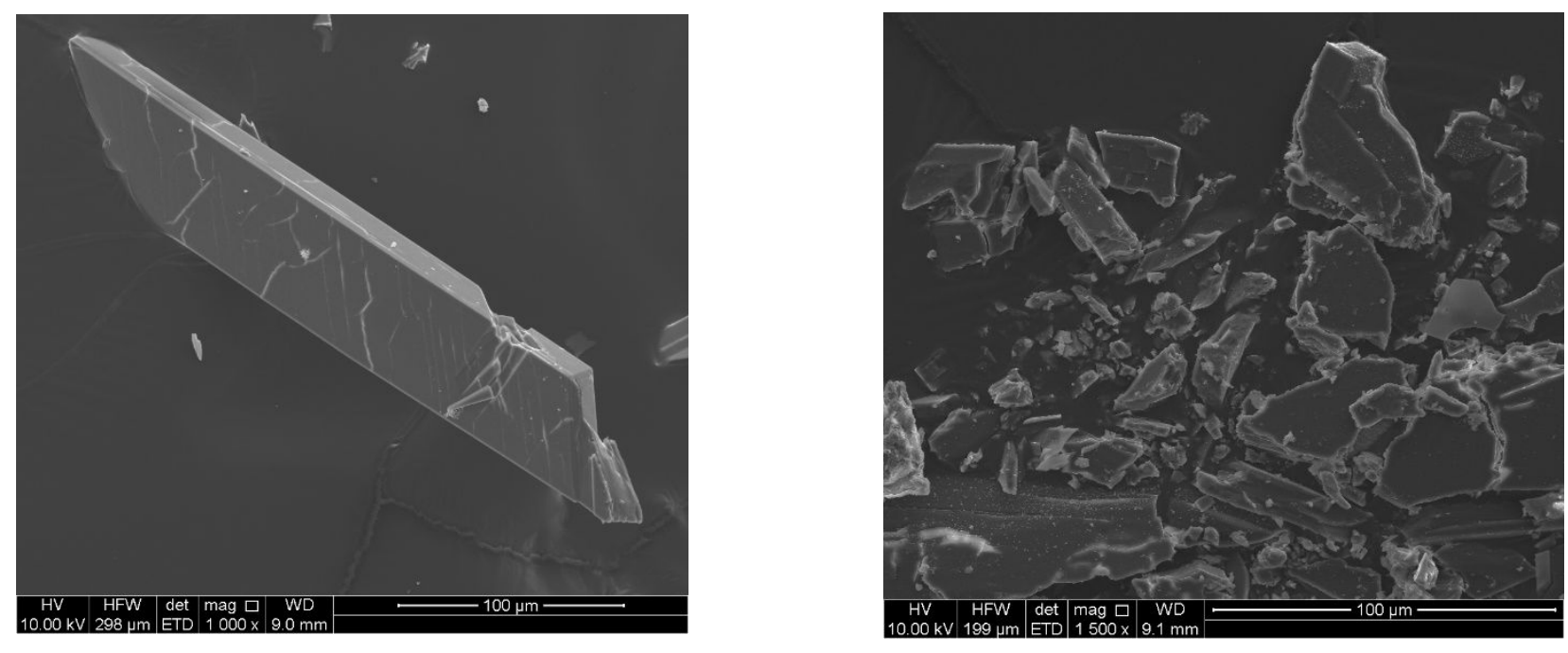

Figure SI 1.2: SEM images of metalated 1 showing (left) a single crystal and (right) an area of crushed crystals used for EDX analysis. 
SI 2.0 High Resolution Transmission Electron Microscopy (HR-TEM), Selected Area Electron Diffraction (SAED) and EDX analysis for 1·NBD-Cl after the hydrogenation

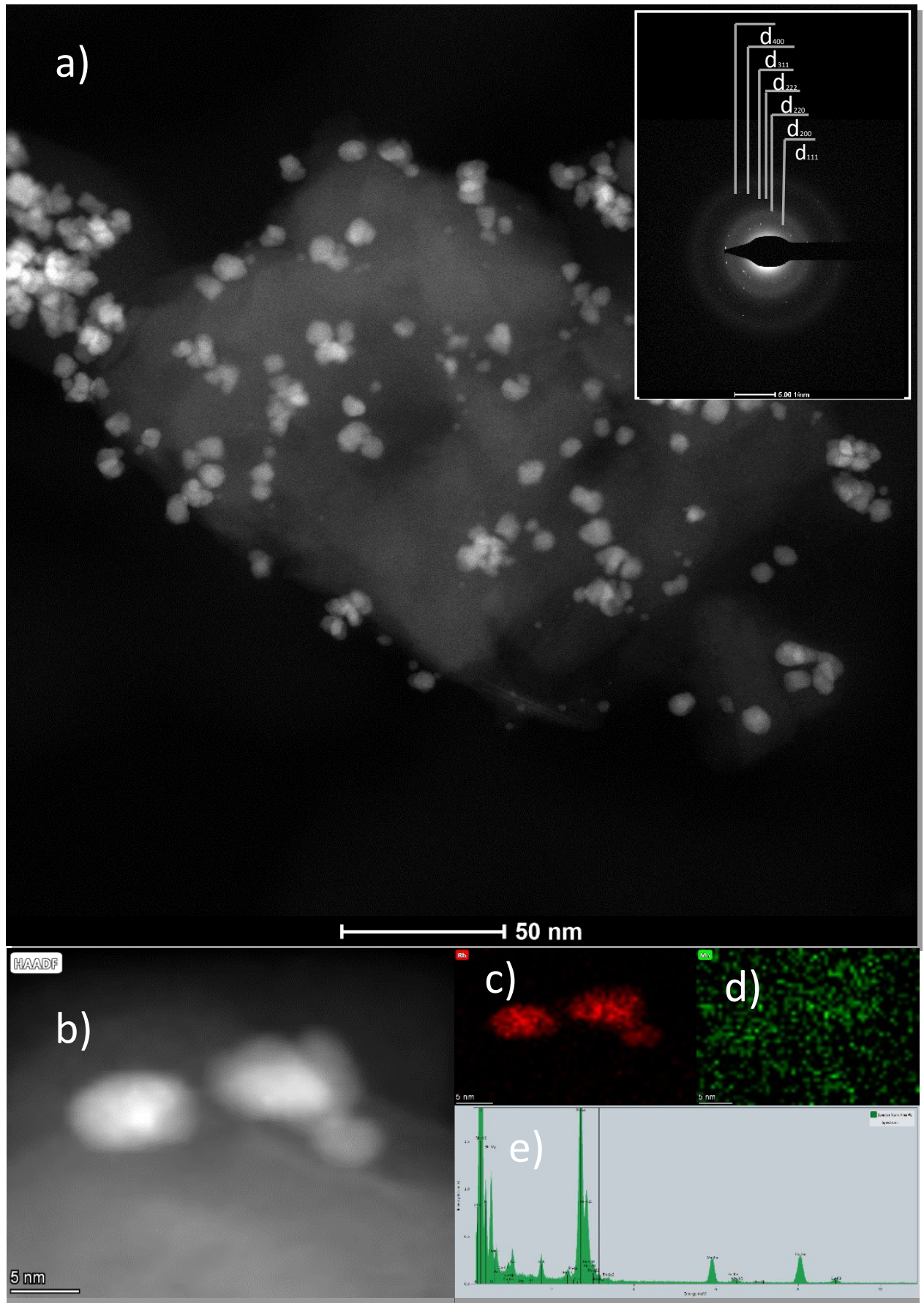

Figure SI 2.1: Characterisation of 1.NBD-Cl after the hydrogenation. a) HR-TEM image with the corresponding SAED as an inset. Nanoparticles show the diffraction from hkl planes which match with corresponding metallic rhodium cubic structure. b) Sketch map of the area selected for EDX element mapping of c) Rhodium, d) Manganese and e) the corresponding spectra. 
SI 3.0 Transmission Electron Microscopy (TEM) data and particle size analysis for $1 \cdot \mathrm{NBD}-\mathrm{Cl}$ after the hydrogenation

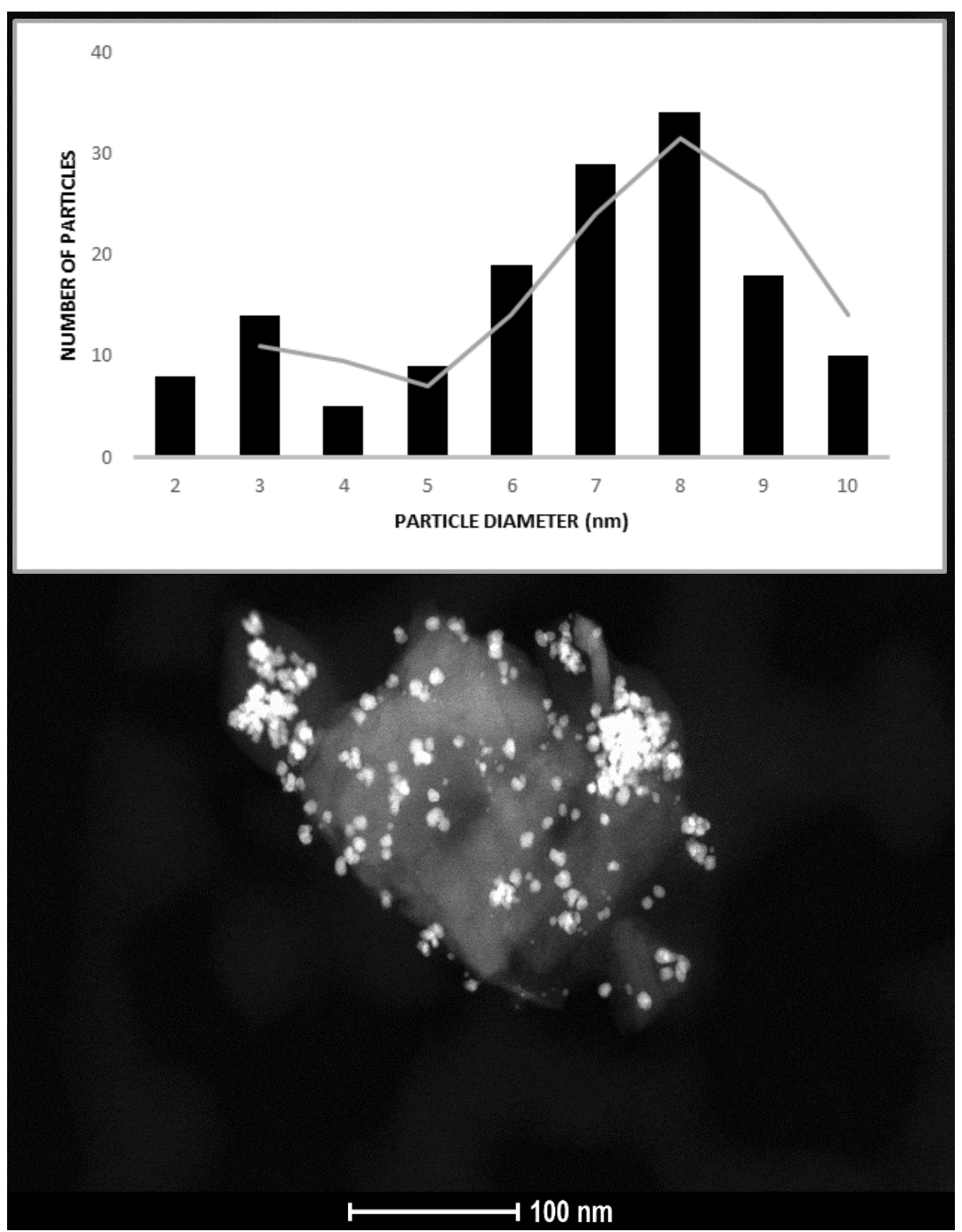

Figure SI 3.1: HR-TEM image revealing the formation of nanoparticles after the hydrogenation of 1.NBD$\mathrm{Cl}$ (bottom). The insert image (top) is the size distribution histogram of the 1·NP with an average of $7 \mathrm{~nm}$. 


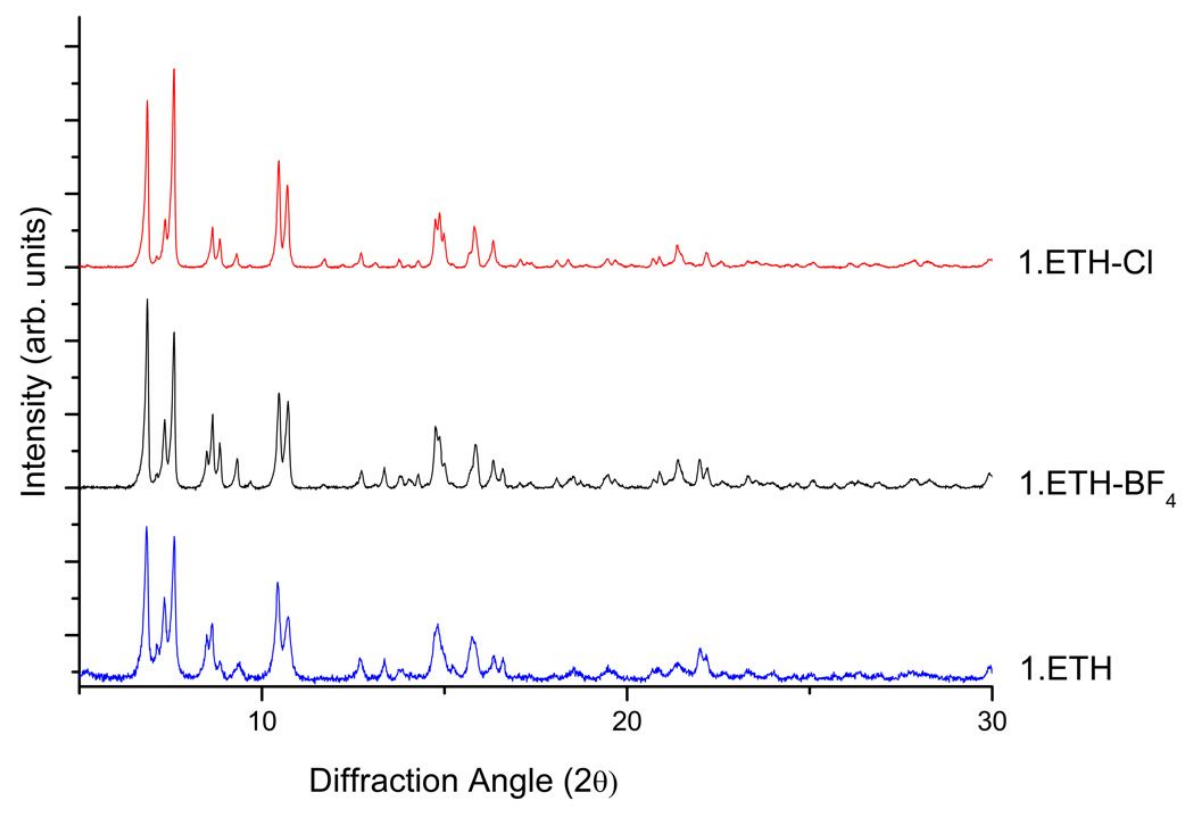

Figure SI 4.1: Experimental PXRD plots for 1-ETH, 1-ETH-BF 4 and 1-ETH-Cl. The flexibility of the framework causes slight shifts in the PXRD peak positions and intensity upon changes in the solvent and loss of solvent during activation or sample preparation for PXRD.

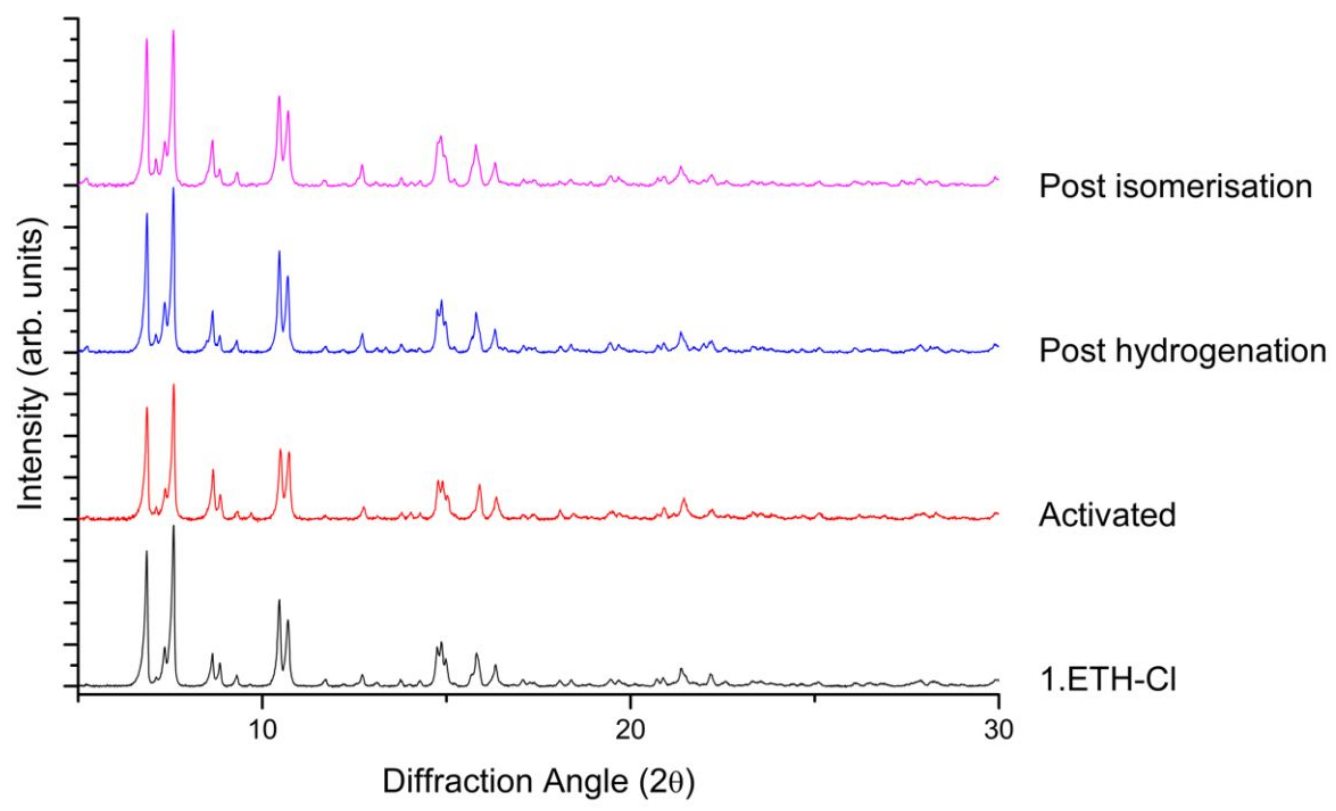

Figure SI 4.2: Experimental PXRD plots for 1·ETH-Cl after activation, hydrogenation and butene isomerisation catalysis. The flexibility of the framework causes slight shifts in the PXRD peak positions and intensity upon changes in the solvent and loss of solvent during activation or sample preparation for PXRD. 


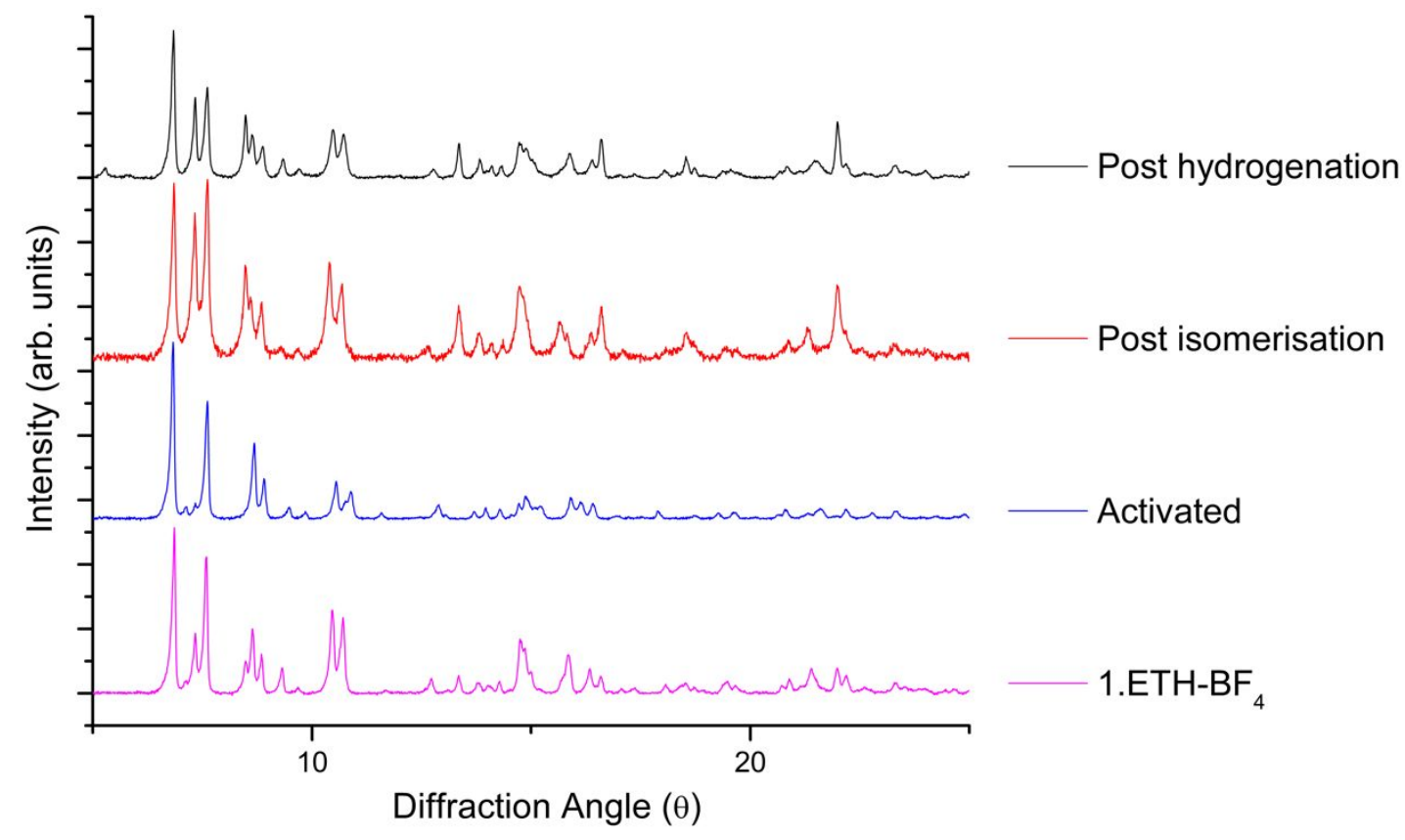

Figure SI 4.3: Experimental PXRD plots for 1.ETH-BF 4 after activation, hydrogenation and butene isomerisation catalysis. The flexibility of the framework causes slight shifts in the PXRD peak positions and intensity upon changes in the solvent and loss of solvent during activation or sample preparation for PXRD. 


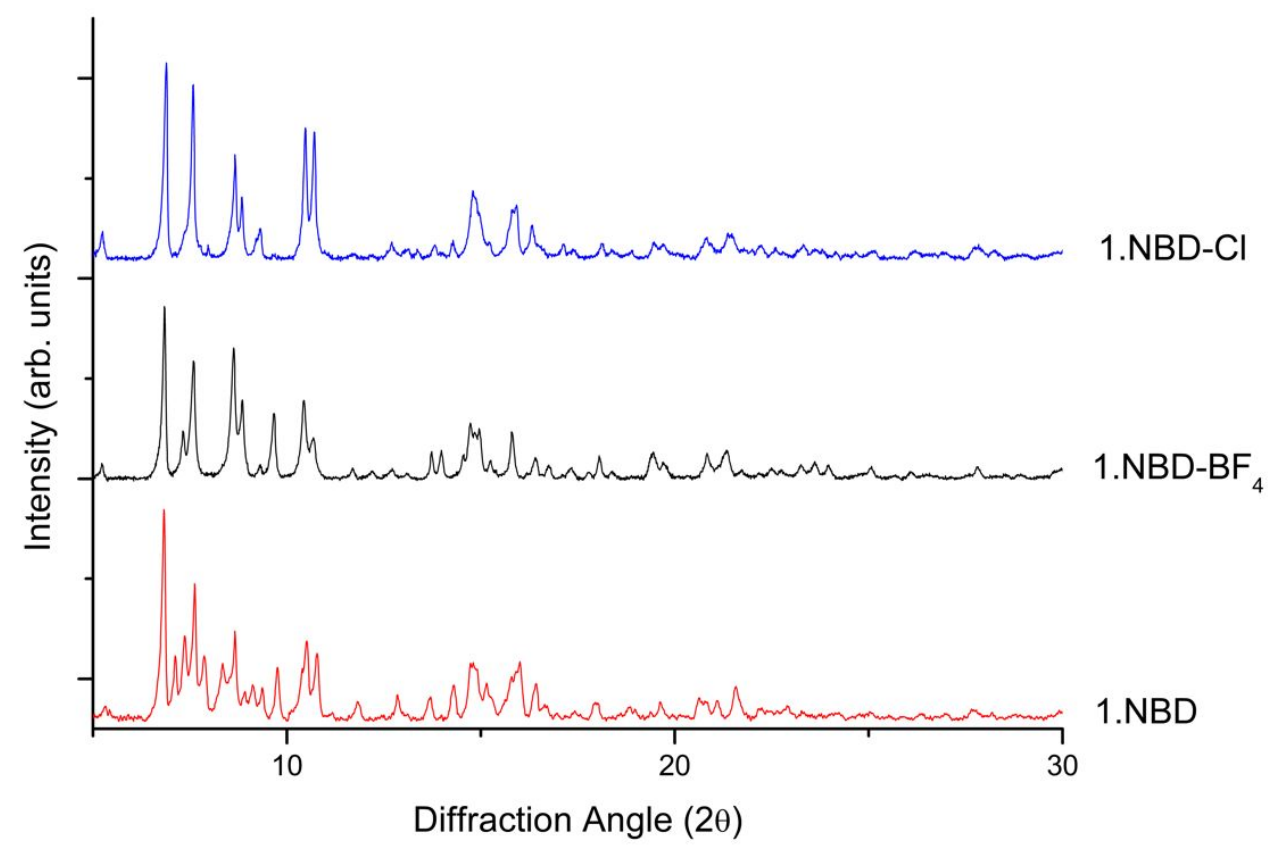

Figure SI 4.4: Experimental PXRD plots for 1·NBD, 1·NBD-BF ${ }_{4}$ and 1·NBD-Cl. The flexibility of the framework causes slight shifts in the PXRD peak positions and intensity upon changes in the solvent and loss of solvent during activation or sample preparation for PXRD.

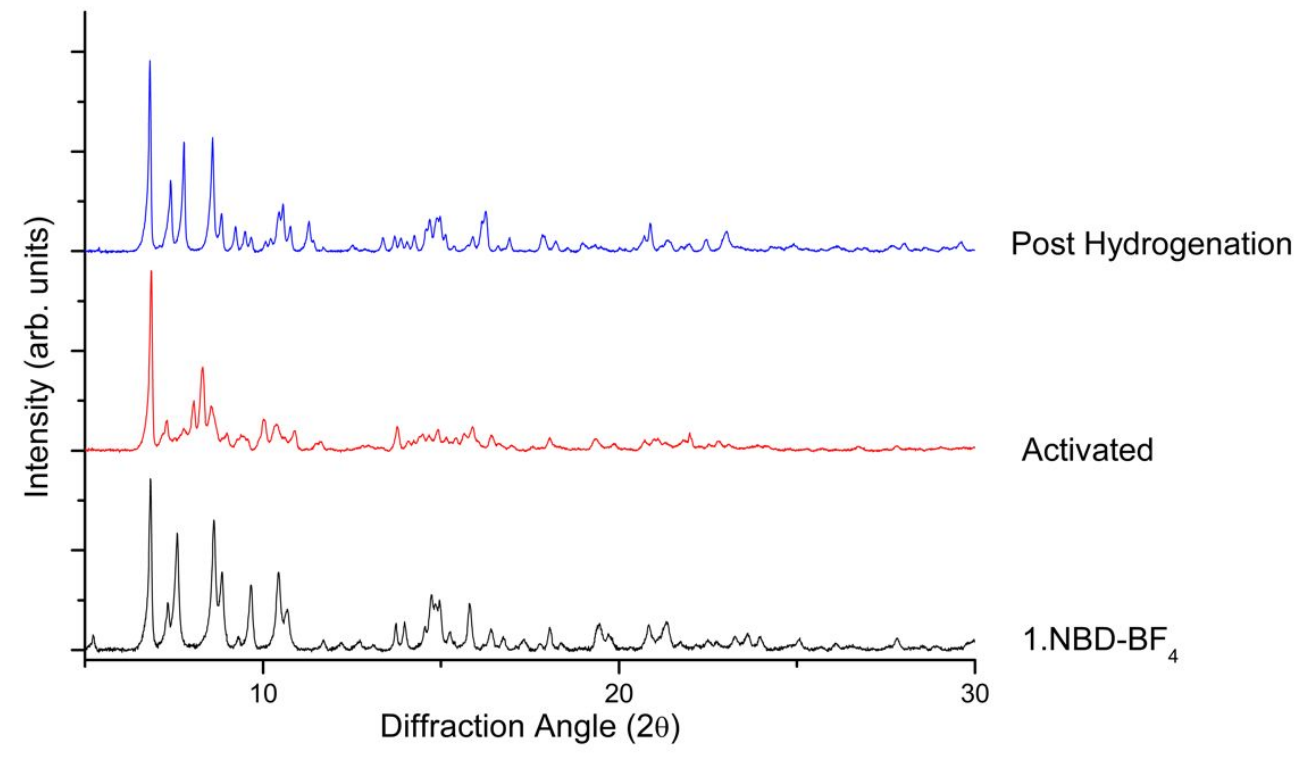

Figure SI 4.5: Experimental PXRD plots for 1-NBD-BF 4 after activation and hydrogenation. The flexibility of the framework causes slight shifts in the PXRD peak positions and intensity upon changes in the solvent and loss of solvent during activation or sample preparation for PXRD. 


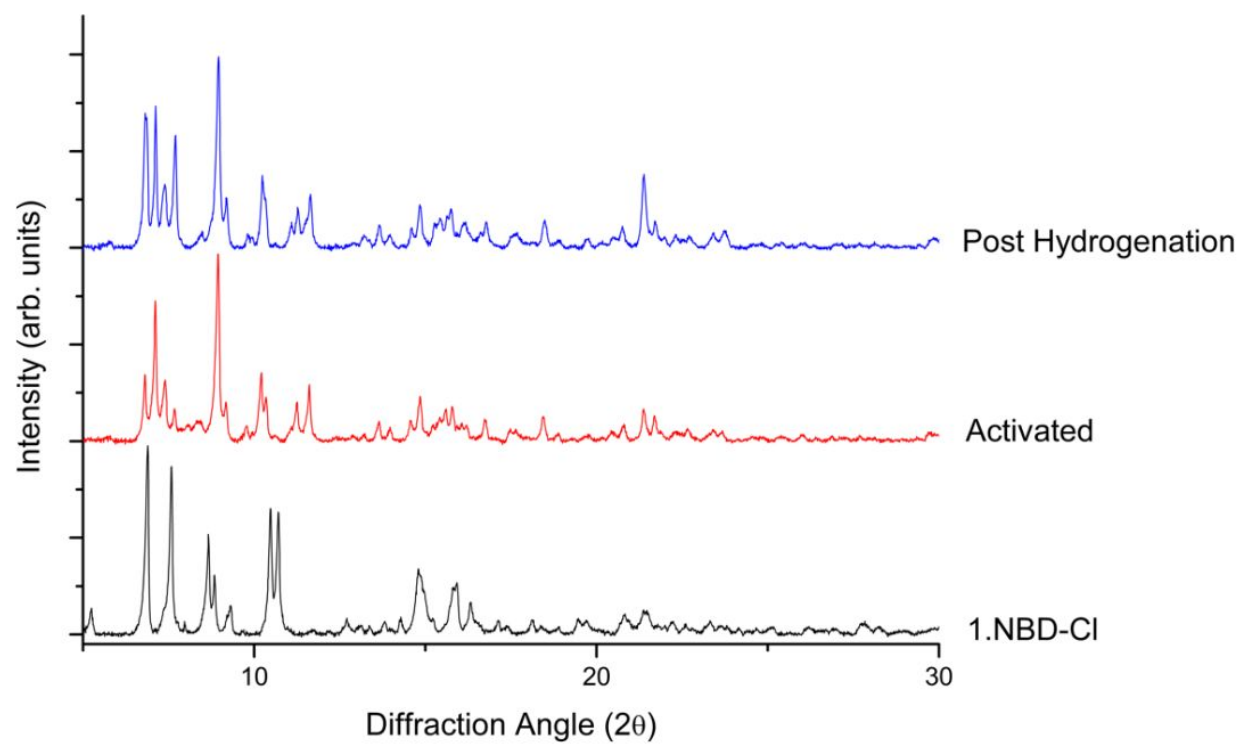

Figure SI 4.6: Experimental PXRD plots for 1.NBD-Cl after activation and hydrogenation. The flexibility of the framework causes slight shifts in the PXRD peak positions and intensity upon changes in the solvent and loss of solvent during activation or sample preparation for PXRD.

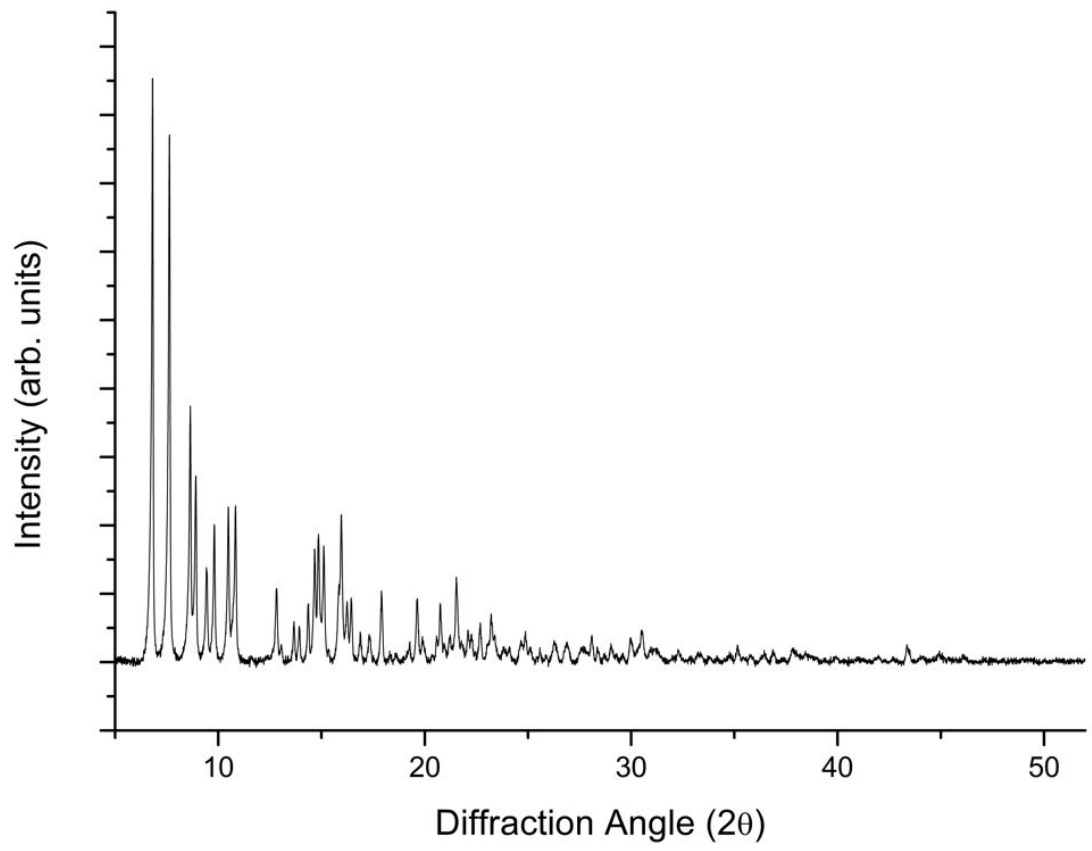

Figure SI 4.7: Experimental PXRD plot for 1.NP. The rhodium nanoparticles formed during hydrogenation are too small to produce discernible peaks in the PXRD pattern. The flexibility of the framework causes slight shifts in the PXRD peak positions and intensity upon changes in the solvent and loss of solvent during activation or sample preparation for PXRD. 


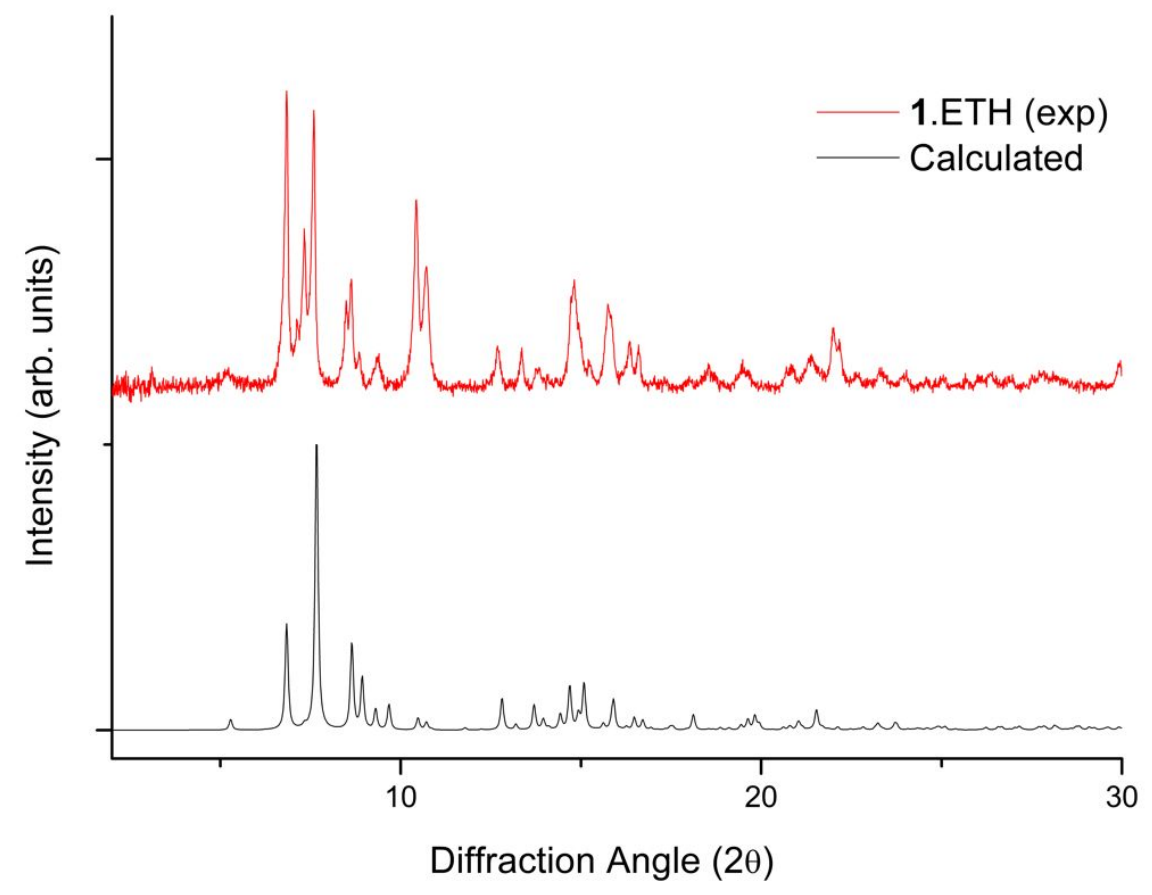

Figure SI 4.8: Calculated and experimental PXRD plots for 1-ETH. The flexibility of the framework causes slight shifts in the PXRD peak positions and intensity upon changes in the solvent and loss of solvent during activation or sample preparation for PXRD.

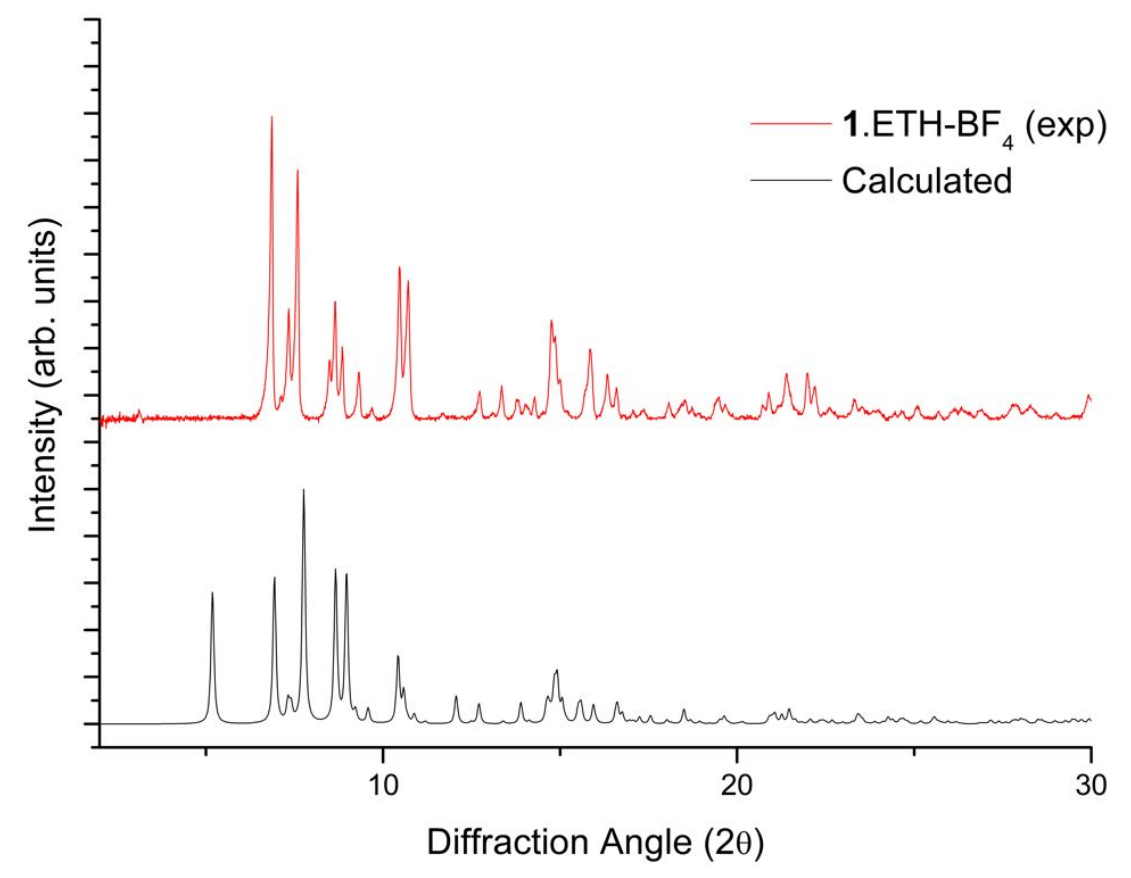

Figure SI 4.9: Calculated and experimental PXRD plots for 1-ETH-BF 4 . The flexibility of the framework causes slight shifts in the PXRD peak positions and intensity upon changes in the solvent and loss of solvent during activation or sample preparation for PXRD. 


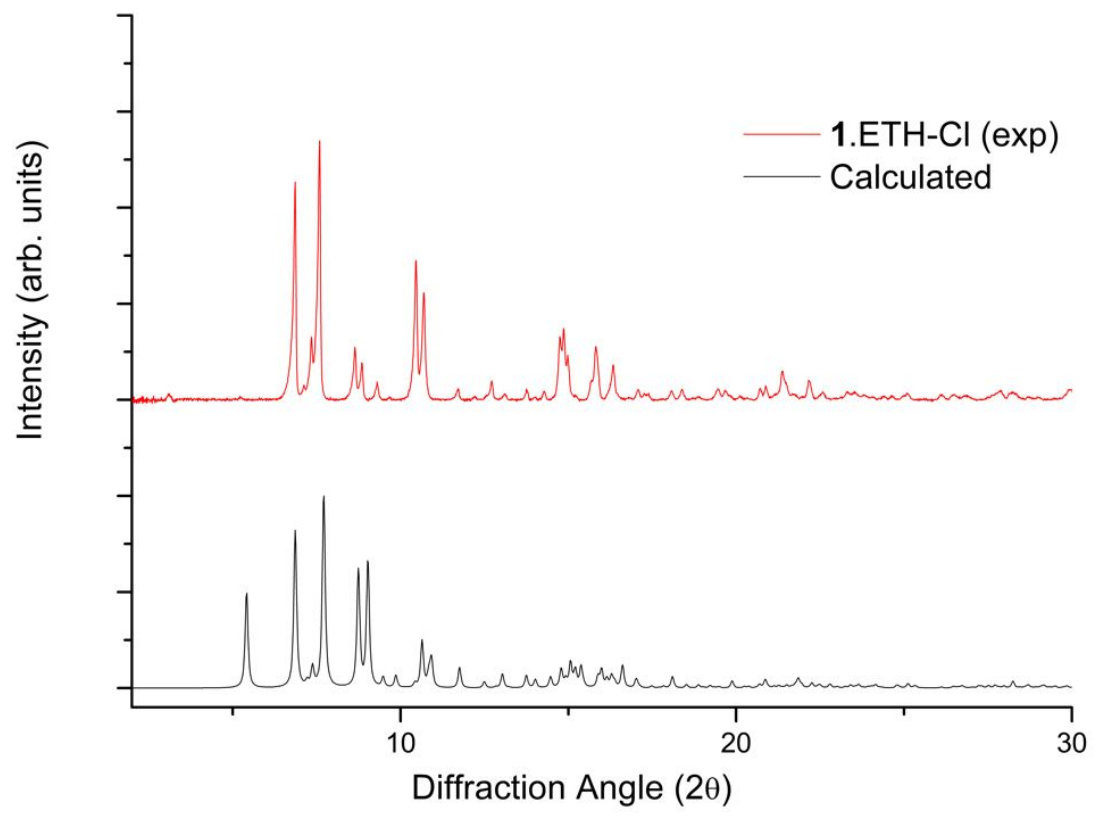

Figure SI 4.10: Calculated and experimental PXRD plots for 1.ETH-Cl. The flexibility of the framework causes slight shifts in the PXRD peak positions and intensity upon changes in the solvent and loss of solvent during activation or sample preparation for PXRD.

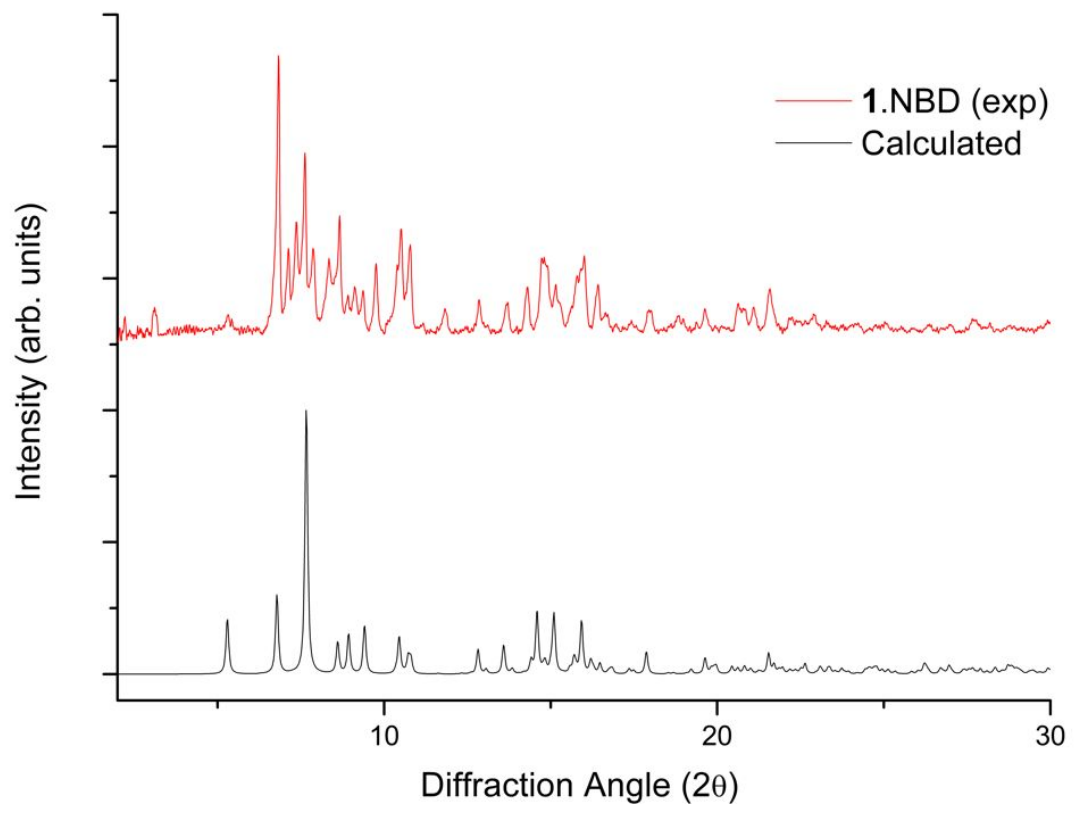

Figure SI 4.11: Calculated and experimental PXRD plots for 1.NBD. The flexibility of the framework causes slight shifts in the PXRD peak positions and intensity upon changes in the solvent and loss of solvent during activation or sample preparation for PXRD. 


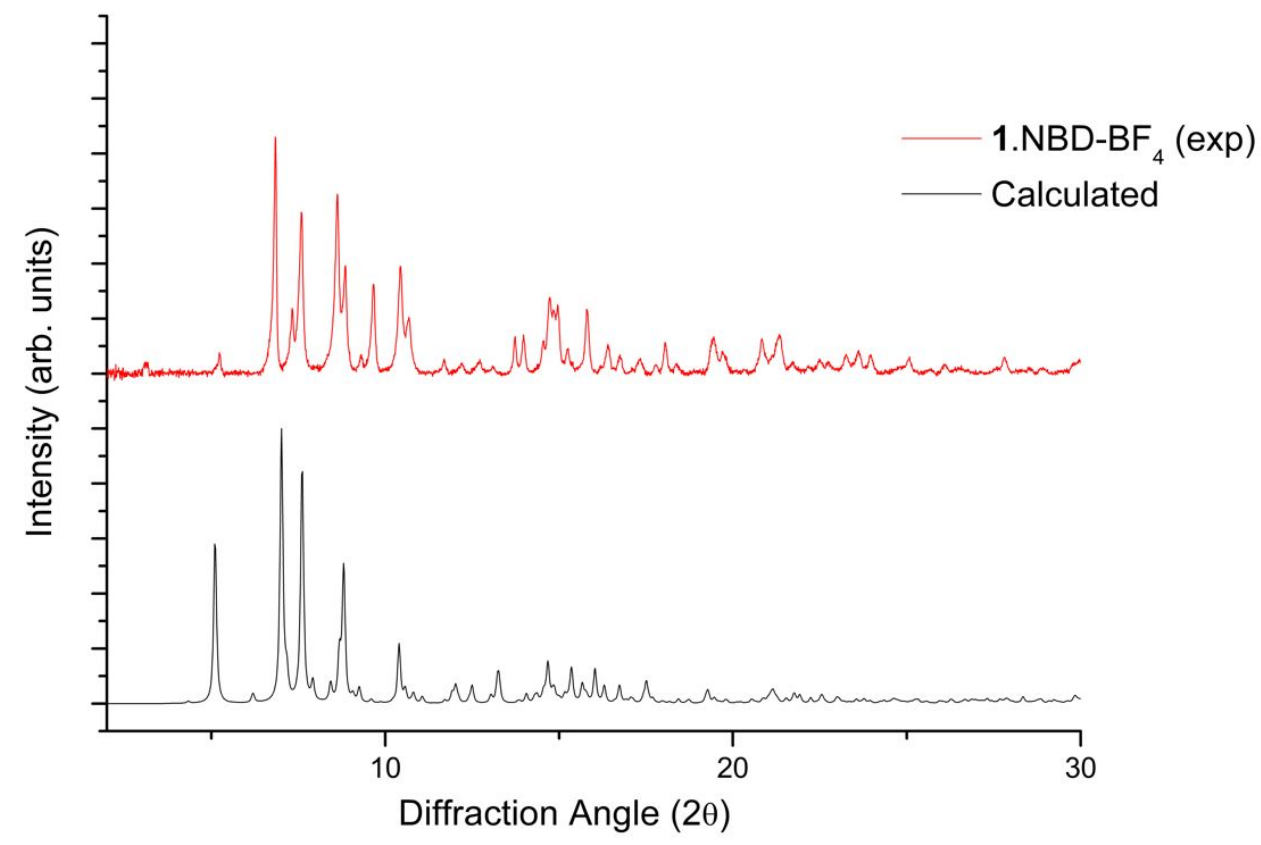

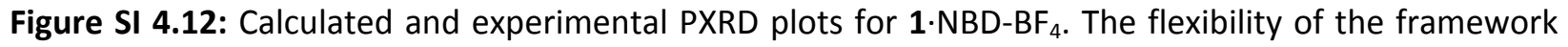
causes slight shifts in the PXRD peak positions and intensity upon changes in the solvent and loss of solvent during activation or sample preparation for PXRD.

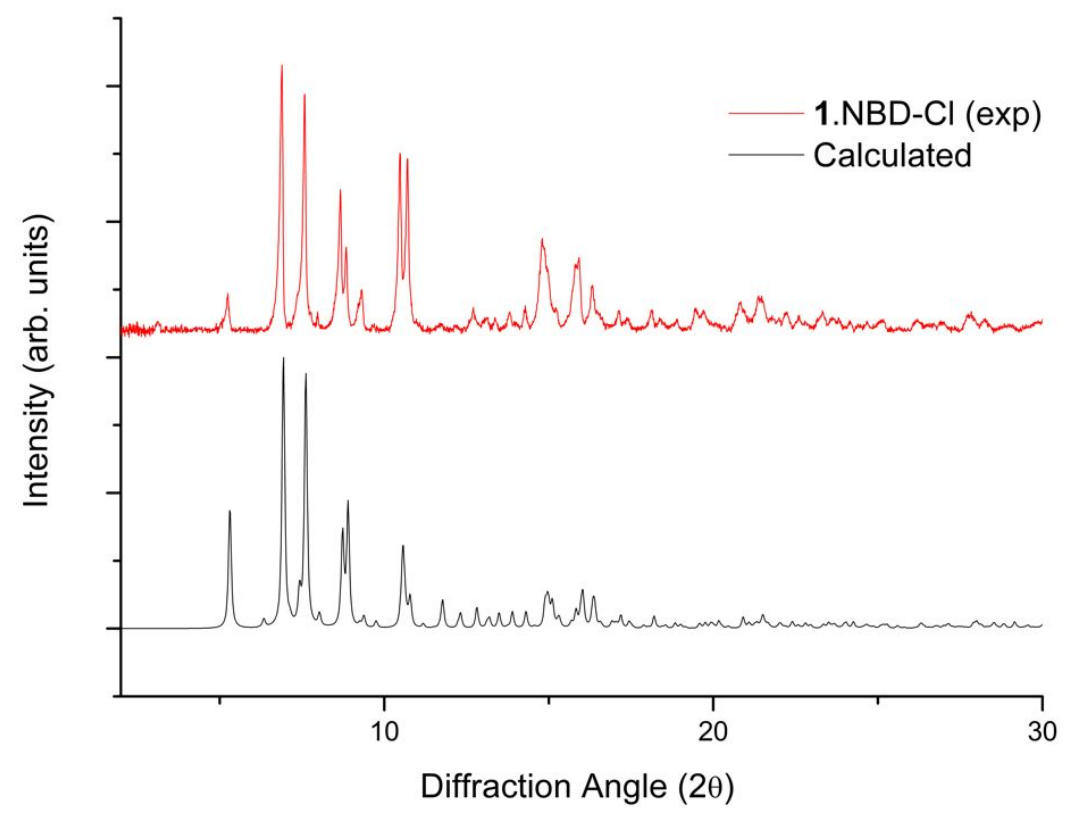

Figure SI 4.13: Calculated and experimental PXRD plots for 1-ETH-Cl. The flexibility of the framework causes slight shifts in the PXRD peak positions and intensity upon changes in the solvent and loss of solvent during activation or sample preparation for PXRD. 


\section{SI 5.0 Single Crystal X-ray Crystallography}

\section{SI 5.1 General Procedures}

Single crystals were mounted in Paratone-N oil on a MiTeGen micromount. Single-crystal X-ray data were collected at $100 \mathrm{~K}$ on the MX1 or MX2 beamlines of the Australian Synchrotron ${ }^{1}$ using the Blue-ice software interface, ${ }^{2} \lambda=0.71073 \AA$. Absorptions corrections were applied using empirical methods using $\mathrm{SHELXS}^{3}$ or SHELXT ${ }^{4}$ [ref] and refined by full-matrix least squares on $\mathrm{F}^{2}$ by SHELXL, ${ }^{5}$ interfaced through the program X-Seed ${ }^{6}$ or OLEX. ${ }^{7}$ In general, all atoms were refined anisotropically and hydrogens atoms were included as invariants at geometrically estimated positions, unless specified otherwise in additional details in supporting information. Where noted, the data was treated with the SQUEEZE routine available in Platon. ${ }^{8}$ Figures were produced using the program CrystalMaker. X-ray experimental data is given in Tables S3 - S5. CIF data have been deposited with the Cambridge Crystallographic Data Centre, CCDC reference numbers CCDC 2003247-2003253.

\section{SI 5.2 Specific Refinement Details}

1-[Rh(NBD)][Rh(NBD)Cl $]$ (1-NBD). The crystals were mounted from acetonitrile (MeCN). A series of DFIX, SIMU, RIGU and ISOR restraints were used to model the NBD ligands of the main moiety and the anion. The $\left[\mathrm{Rh}(\mathrm{NBD}) \mathrm{Cl}_{2}\right]$ anion is disordered over two sites but the NBD ligand of the minor component could not be located in the difference map (one $\mathrm{Cl}$ ligand lies in the anion pocket of the MOF and is not disordered). The SQUEEZE routine available in Platon was applied to the data, which gave a new HKL file. The number of located electrons was 72 and electron density equating to approximately 1.5 additional MeCN (22e) molecules per formula unit were removed by the SQUEEZE routine. There are also $3 \mathrm{MeCN}$ molecules per formula unit that were located in the structure and refined.

1-[Rh(NBD)]Cl (1-NBD-Cl). The crystals were mounted from methanol (MeOH). A series of DFIX, SIMU, and ISOR restraints were used to model the NBD ligands of the main moiety. The chloride anion is disordered over two sites. The SQUEEZE routine available in Platon was applied to the data, which gave a new HKL file. The number of located electrons was 1188 and electron density equating to approximately 16.5 additional $\mathrm{MeOH}(18 \mathrm{e})$ molecules per formula unit were removed by the SQUEEZE routine.

1.[Rh(NBD)]BF 4 (1-NBD-BF 4 ). The crystals were mounted from methanol (MeOH). The data was of sufficient quality to allow the location and refinement of the methanol (and what appears to be water molecules). A series of DFIX, EADP, and ISOR restraints were used to model the solvate molecules. The hydrogen atoms associated with the water molecules were added to the formula.

1. $\left[\mathrm{Rh}\left(\mathrm{CH}_{2} \mathrm{CH}_{2}\right)_{2}\right]\left[\mathrm{Rh}\left(\mathrm{CH}_{2} \mathrm{CH}_{2}\right) \mathrm{Cl}_{2}\right](1 \cdot \mathrm{ETH})$. The crystals were mounted from ethanol (EtOH). A series of DFIX and SIMU restraints were used to model the primary coordination sphere of the Rh in the main moiety and the anion. FLAT and SIMU restraints were used to model an aryl ring of the ligand. The SQUEEZE routine available in Platon was applied to the data, which gave a new HKL file. The number of located electrons was 573 and electron density equating to approximately $11 \mathrm{EtOH}$ (26e) molecules per formula unit were removed by the SQUEEZE routine.

1. $\left[\mathrm{Rh}\left(\mathrm{CH}_{2} \mathrm{CH}_{2}\right)_{2}\right] \mathrm{Cl}(\mathbf{1} \cdot \mathrm{ETH}-\mathrm{Cl})$. The crystals were mounted from pentane. A series of DFIX and SIMU restraints were used to model the primary coordination sphere of the Rh in the main moiety. SIMU restraints were used to model the chelating site of the MOF. The SQUEEZE routine available in Platon was applied to the 
data, which gave a new HKL file. The number of located electrons was 455 and electron density equating to approximately 5.5 pentane (42e) molecules per formula unit were removed by the SQUEEZE routine.

1. $\left[\mathrm{Rh}\left(\mathrm{CH}_{2} \mathrm{CH}_{2}\right)_{2}\right] \mathrm{BF}_{4}\left(\mathbf{1} \cdot \mathrm{ETH}-\mathrm{BF}_{4}\right)$. The crystals were mounted from pentane. A series of DFIX and EADP restraints were used to model the disordered tetrafluoroborate anion (across two sites). The SQUEEZE routine available in Platon was applied to the data, which gave a new HKL file. The number of located electrons was 468 and electron density equating to approximately 5.5 pentane (42e) molecules per formula unit were removed by the SQUEEZE routine.

1- $\left[\mathrm{Rh}(\mathrm{MeCN})_{2}\right] \mathrm{Cl}$. The crystals were mounted from tetrahydrofuran (THF). The $\mathrm{Rh}(\mathrm{MeCN})_{2} \mathrm{Cl}$ moiety was modelled at $70 \%$ occupancy ( 0.35 due to the mirror plane) despite EDX data supporting quantitative metalation. The SQUEEZE routine available in Platon was applied to the data, which gave a new HKL file. The number of located electrons was 443 and electron density equating to approximately 5.5 THF (40e) molecules per formula unit were removed by the SQUEEZE routine. 

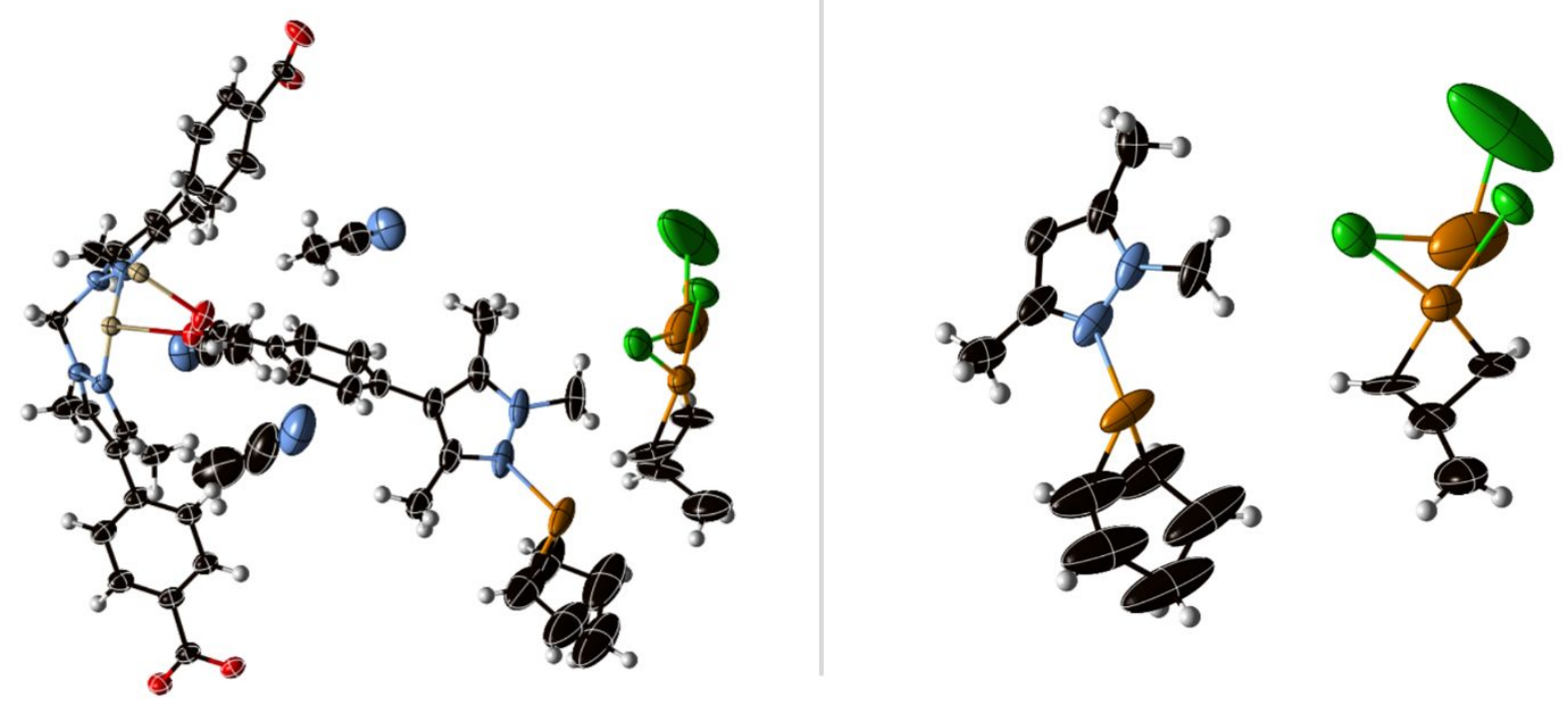

Figure SI 5.3.1: (left) The asymmetric unit of 1·[Rh(NBD)][Rh(NBD)Cl $\left.\mathrm{Cl}_{2}\right]$, with all non-hydrogen atoms represented by ellipsoids at the $50 \%$ probability level ( $\mathrm{C}$, black; $\mathrm{H}$, white; $\mathrm{N}$, light blue; $\mathrm{O}$, red; Rh, orange; $\mathrm{Mn}$, beige; $\mathrm{Cl}$, green ). (right) A perspective view of the $\mathrm{Rh}(\mathrm{I})$ chelation site and associated $\left[\mathrm{Rh}(\mathrm{NBD}) \mathrm{Cl}_{2}\right]$ anion (disorder shown) in $\mathbf{1} \cdot[\mathrm{Rh}(\mathrm{NBD})]\left[\mathrm{Rh}(\mathrm{NBD}) \mathrm{Cl}_{2}\right]$ with all non-hydrogen atoms represented by ellipsoids at the $50 \%$ probability level.

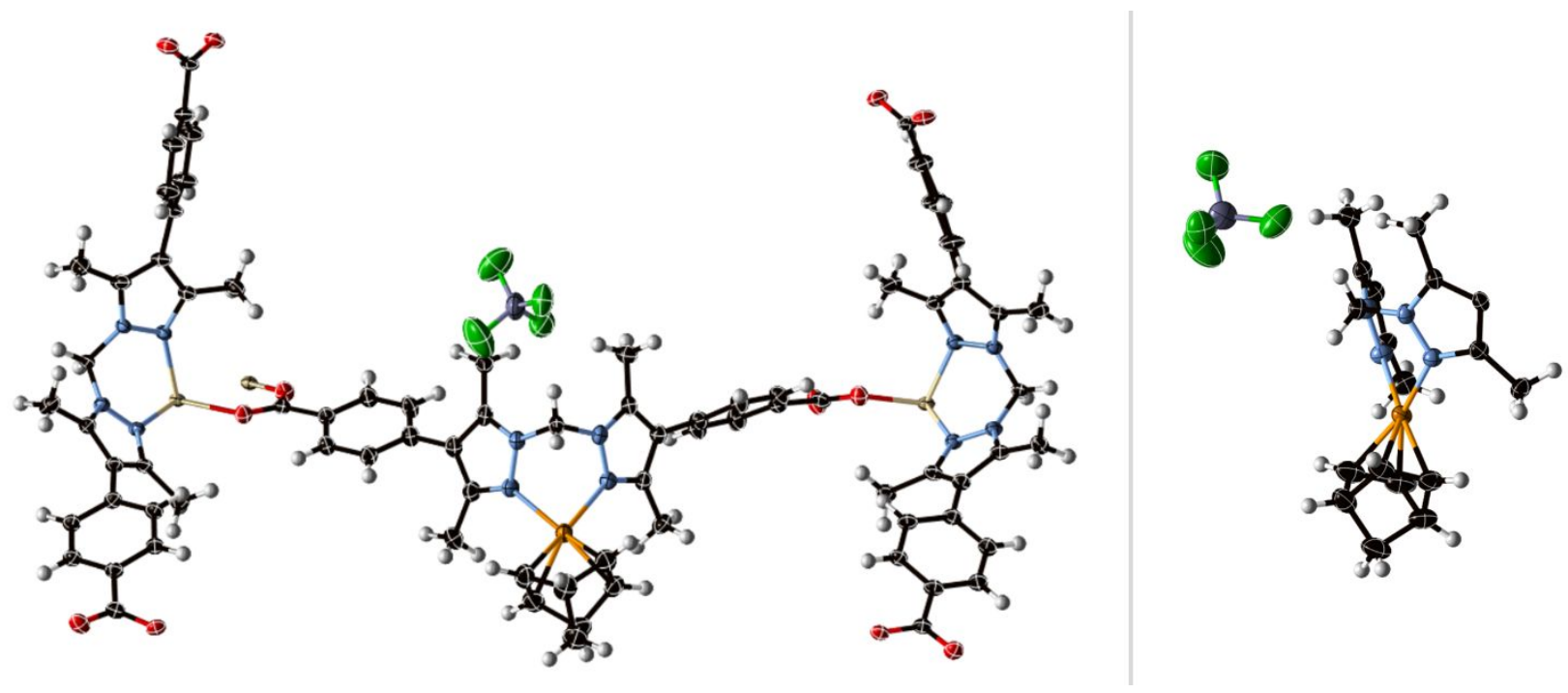

Figure SI 5.3.2: (left) The asymmetric unit of 1.NBD-BF 4 , with all non-hydrogen atoms represented by ellipsoids at the $50 \%$ probability level (C, black; $\mathrm{H}$, white; N, light blue; O, red; Rh, orange; $\mathrm{Mn}$, beige; $\mathrm{B}$,

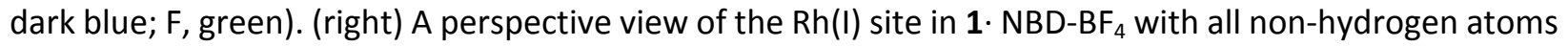
represented by ellipsoids at the $50 \%$ probability level. 

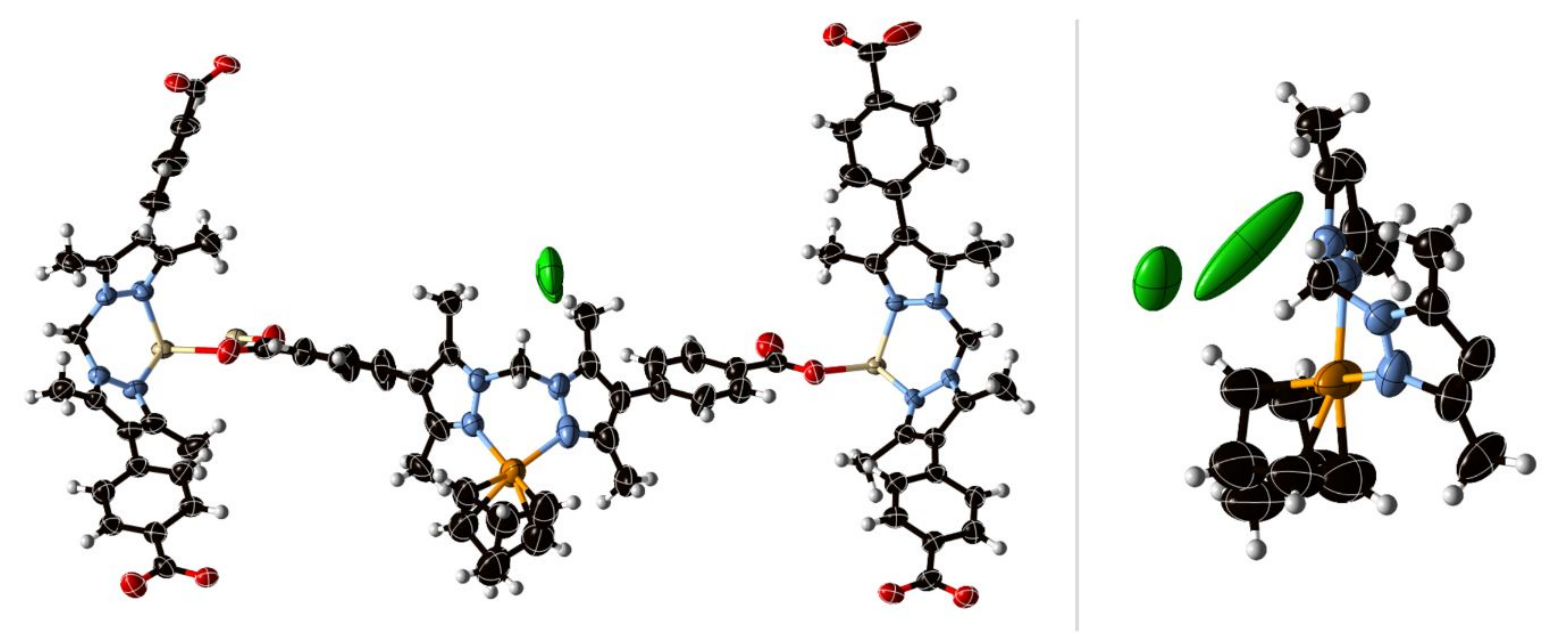

Figure SI 5.3.3: (left) The asymmetric unit of 1-NBD-Cl, with all non-hydrogen atoms represented by ellipsoids at the $50 \%$ probability level (C, black; $\mathrm{H}$, white; $\mathrm{N}$, light blue; $\mathrm{O}$, red; $\mathrm{Rh}$, orange; $\mathrm{Mn}$, beige; $\mathrm{Cl}$, green). (right) A perspective view of the $\mathrm{Rh}(\mathrm{I})$ site and associated chloride anion (disordered over two positions) in 1.NBD-Cl with all non-hydrogen atoms represented by ellipsoids at the $50 \%$ probability level. 

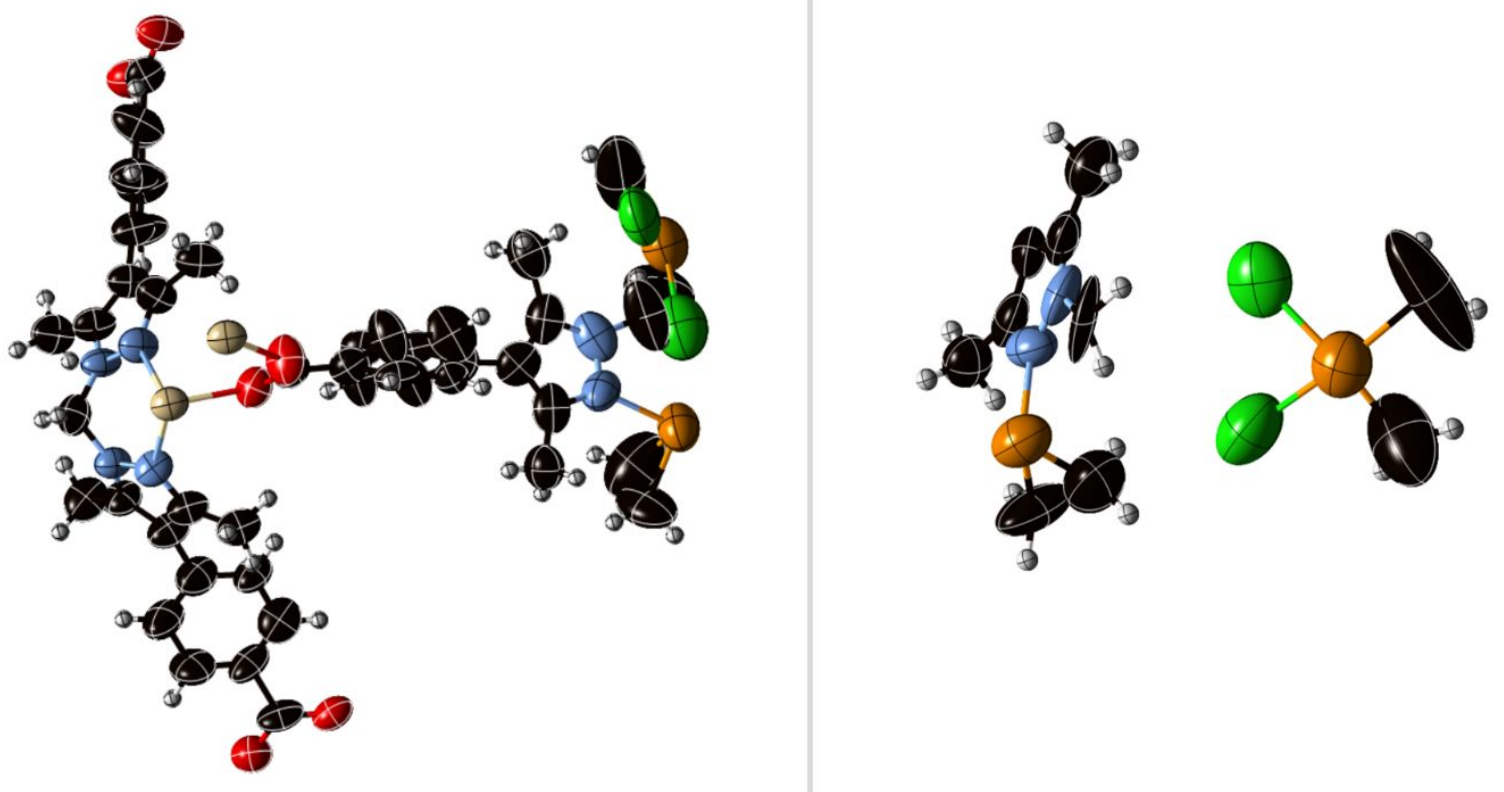

Figure SI 5.3.4: (left) The asymmetric unit of 1·[Rh( $\left.\left(\mathrm{C}_{2} \mathrm{H}_{4}\right)_{2}\right]\left[\mathrm{Rh}\left(\mathrm{C}_{2} \mathrm{H}_{4}\right)_{2} \mathrm{Cl}_{2}\right](\mathbf{1} \cdot \mathrm{ETH})$, with all non-hydrogen atoms represented by ellipsoids at the $50 \%$ probability level ( $\mathrm{C}$, black; $\mathrm{H}$, white; $\mathrm{N}$, light blue; $\mathrm{O}$, red; $\mathrm{Rh}$, orange; $\mathrm{Mn}$, beige; $\mathrm{Cl}$, green). (right) A perspective view of the $\mathrm{Rh}(\mathrm{I})$ chelation site and associated [Rh $\left.\left(\mathrm{C}_{2} \mathrm{H}_{4}\right)_{2} \mathrm{Cl}_{2}\right]$ anion in 1. $\left[\mathrm{Rh}\left(\mathrm{C}_{2} \mathrm{H}_{4}\right)_{2}\right]\left[\mathrm{Rh}\left(\mathrm{C}_{2} \mathrm{H}_{4}\right)_{2} \mathrm{Cl}_{2}\right]$ with all non-hydrogen atoms represented by ellipsoids at the $50 \%$ probability level. 

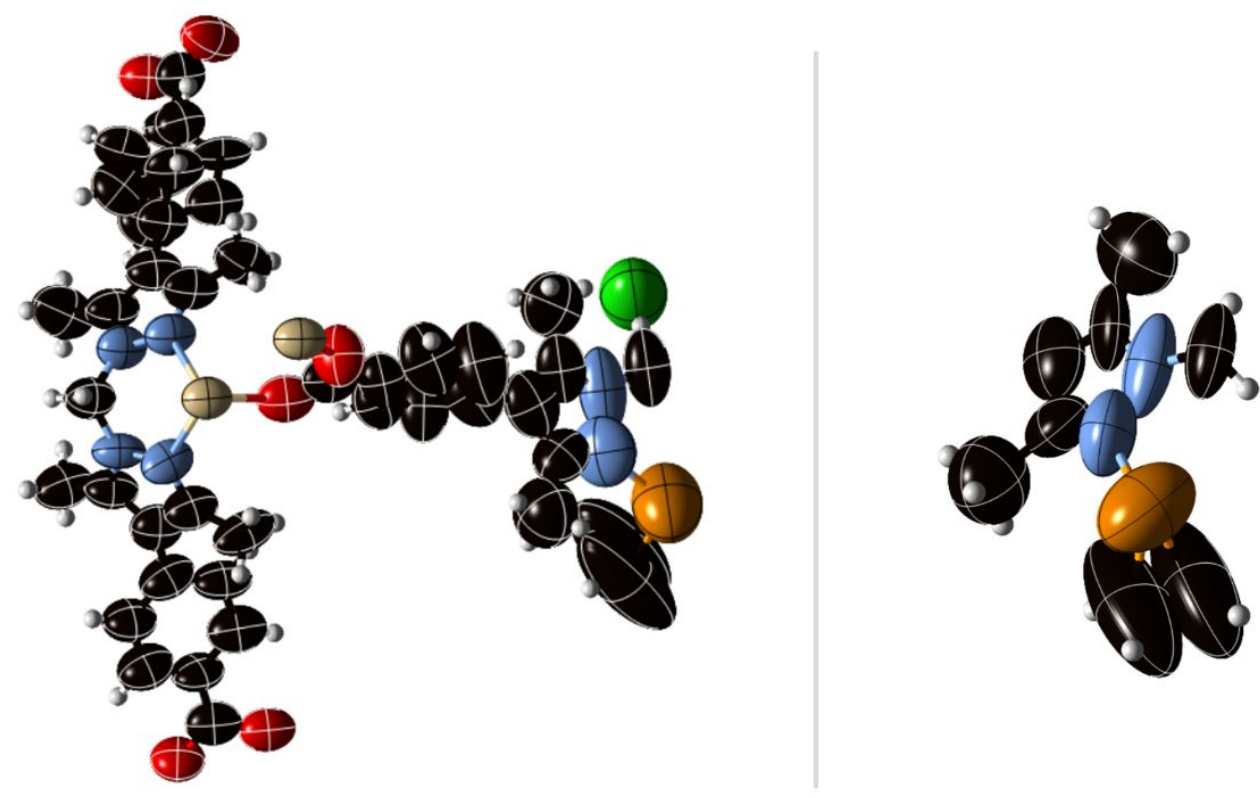

Figure SI 5.3.5: (left) The asymmetric unit of 1.ETH-Cl, with all non-hydrogen atoms represented by ellipsoids at the $50 \%$ probability level (C, black; $\mathrm{H}$, white; $\mathrm{N}$, light blue; $\mathrm{O}$, red; $\mathrm{Rh}$, orange; $\mathrm{Mn}$, beige; $\mathrm{Cl}$, green). (right) A perspective view of the $\mathrm{Rh}(\mathrm{I})$ site and associated chloride anion in 1.ETH-Cl with all nonhydrogen atoms represented by ellipsoids at the $50 \%$ probability level. 

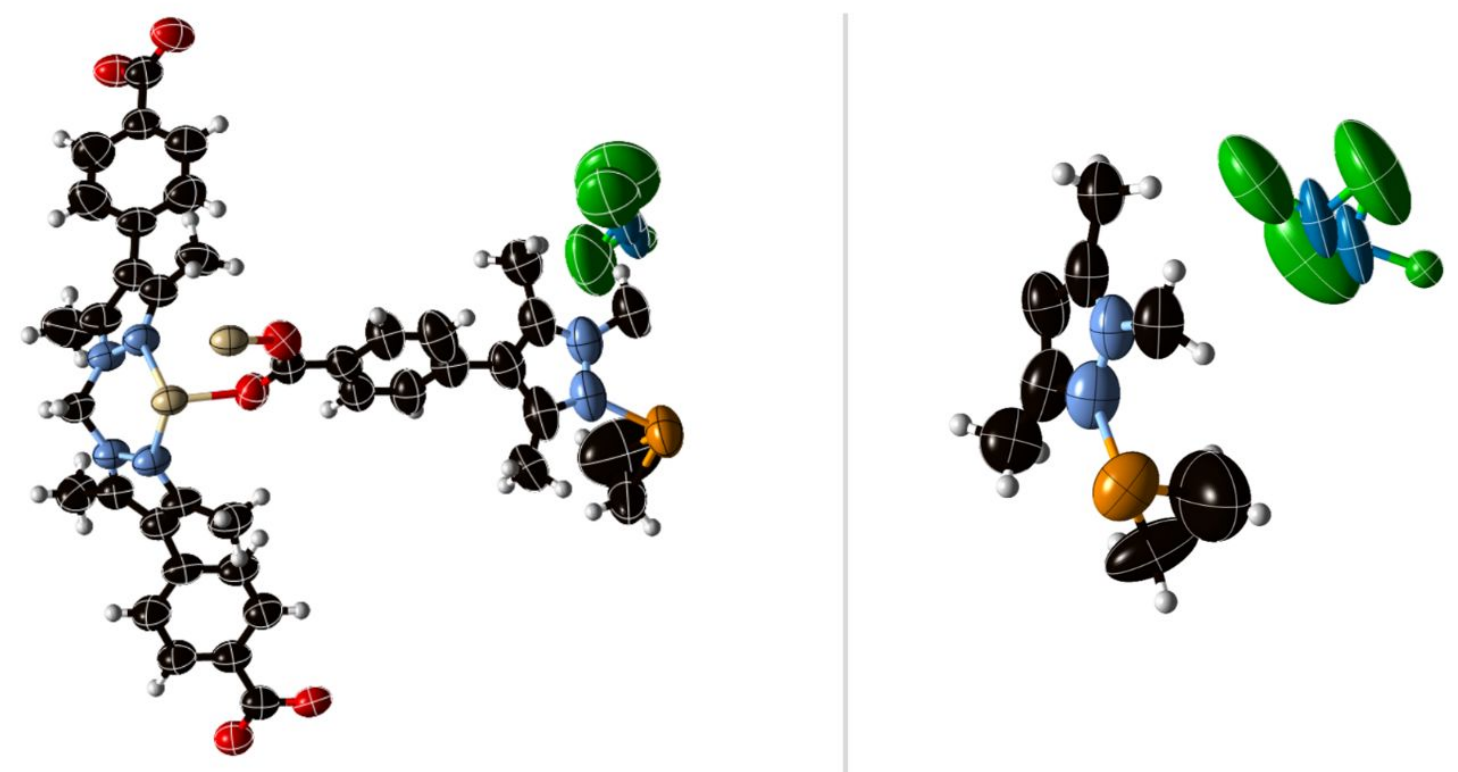

Figure SI 5.3.6: (left) The asymmetric unit of 1.ETH-BF, with all non-hydrogen atoms represented by ellipsoids at the $50 \%$ probability level (C, black; $\mathrm{H}$, white; N, light blue; O, red; Rh, orange; Mn, beige; $\mathrm{B}$,

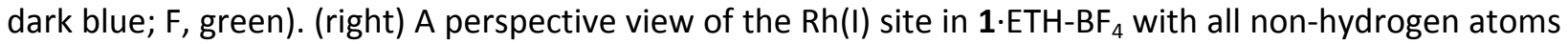
represented by ellipsoids at the $50 \%$ probability level (disorder of the tetrafluoroborate anion shown). 


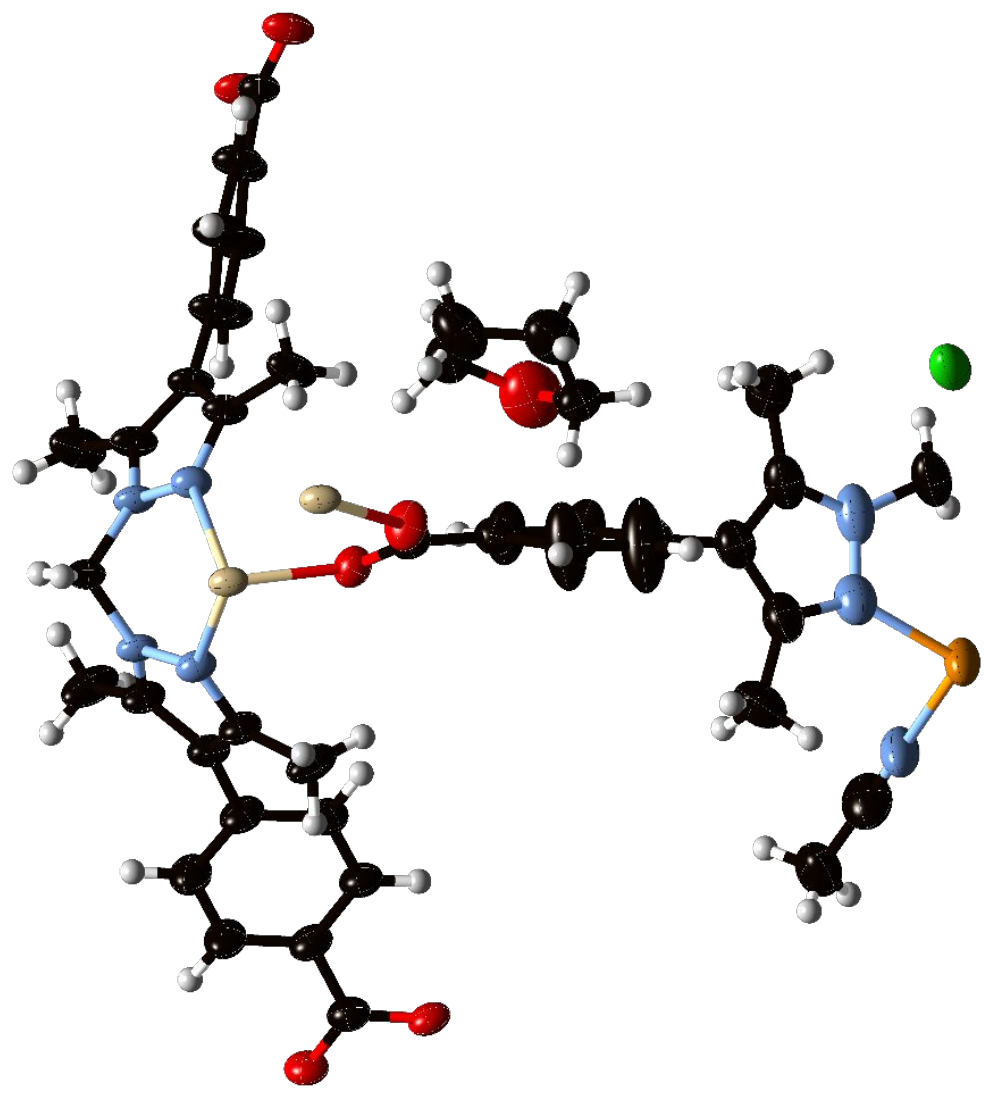

Figure SI 5.3.7: The asymmetric unit of 1.[Rh( $\left.\mathrm{MeCN})_{2}\right] \mathrm{Cl}$, with all non-hydrogen atoms represented by ellipsoids at the $50 \%$ probability level (C, black; $\mathrm{H}$, white; N, light blue; $\mathrm{O}$, red; Rh, orange; $\mathrm{Mn}$, beige; $\mathrm{Cl}$, green). 
SI 5.4 $F_{o b s}$ Electron Density Maps for all structures

a)

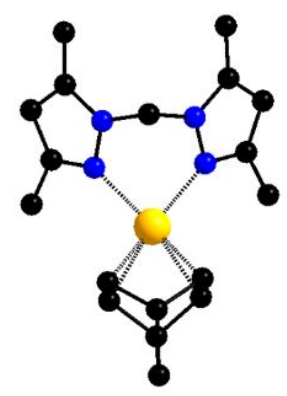

c)

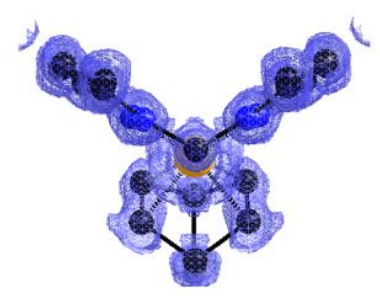

b)

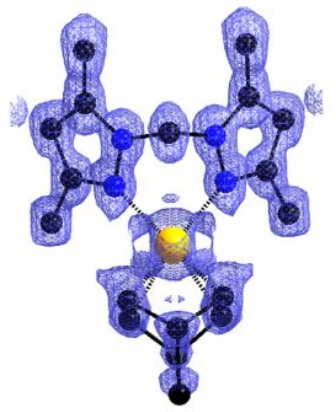

d)

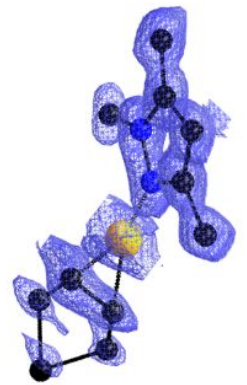

Figure S5.4.1: (a) A perspective view of the chelated $\mathrm{Rh}(\mathrm{I})$ complex in $1 \cdot[\mathrm{Rh}(\mathrm{NBD})]\left[\mathrm{Rh}(\mathrm{NBD}) \mathrm{Cl}_{2}\right]$ and the overlaid electron density map as viewed from the (b) front, (c) top and (d) side of the complex.

a)

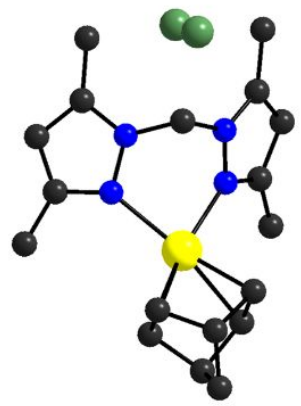

c)

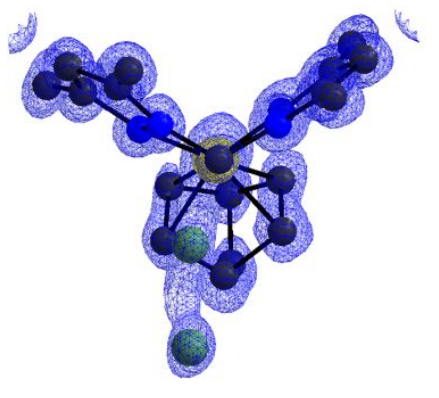

b)

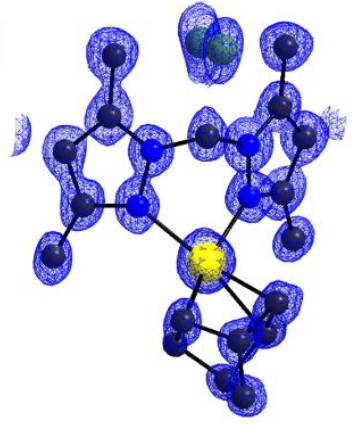

d)

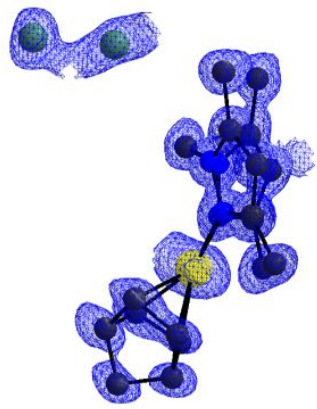

Figure S5.4.2: (a) A perspective view of the chelated $\mathrm{Rh}(\mathrm{I})$ complex in 1-NBD-Cl and the overlaid electron density map as viewed from the (b) front, (c) top and (d) side of the complex. 
a)

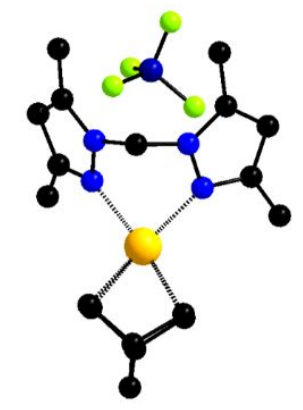

c)

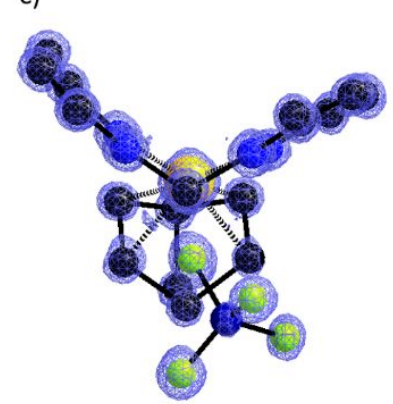

b)

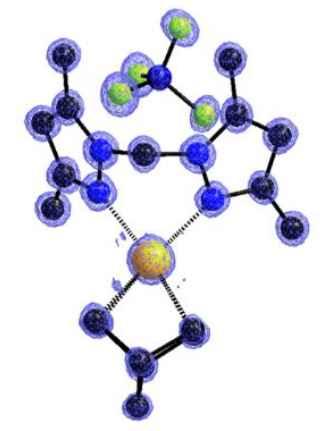

d)

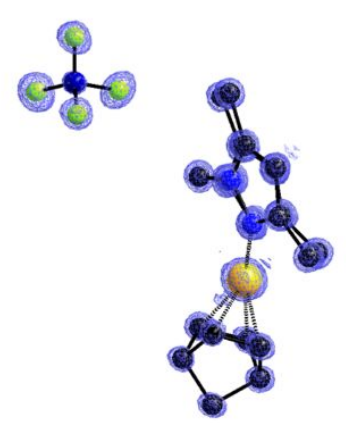

Figure S5.4.3: (a) A perspective view of the chelated $\mathrm{Rh}(\mathrm{I})$ complex in 1·NBD-BF 4 and the overlaid electron density map as viewed from the (b) front, (c) top and (d) side of the complex.

a)

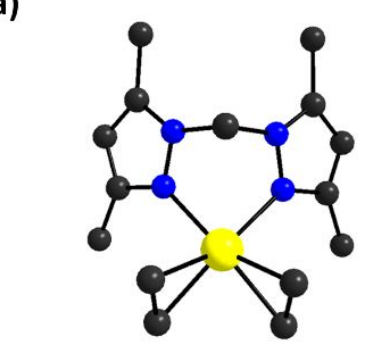

c)

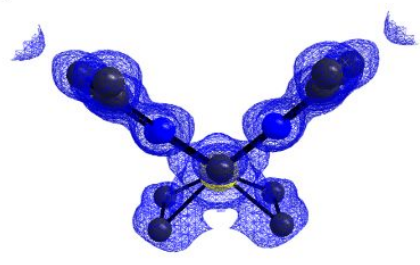

b)

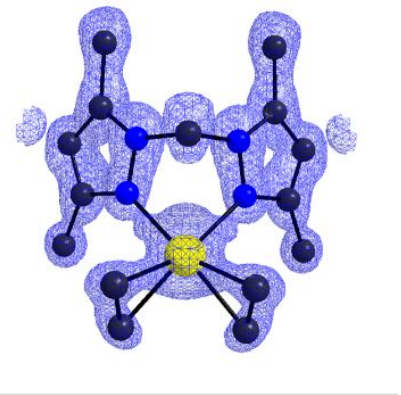

d)

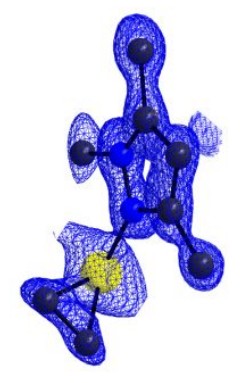

Figure S5.4.4: (a) A perspective view of the chelated $\mathrm{Rh}(\mathrm{I})$ complex in 1. $\left[\mathrm{Rh}\left(\mathrm{C}_{2} \mathrm{H}_{4}\right)_{2}\right]\left[\mathrm{Rh}\left(\mathrm{C}_{2} \mathrm{H}_{4}\right)_{2} \mathrm{Cl}_{2}\right](\mathbf{1} \cdot \mathrm{ETH})$ and the overlaid electron density map as viewed from the (b) front, (c) top and (d) side of the complex. 
a)

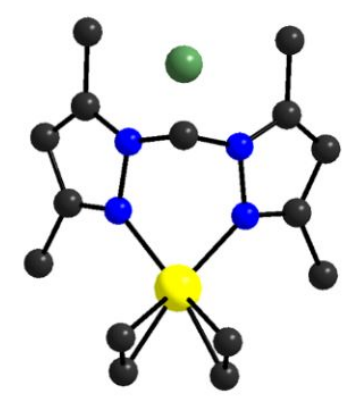

c)

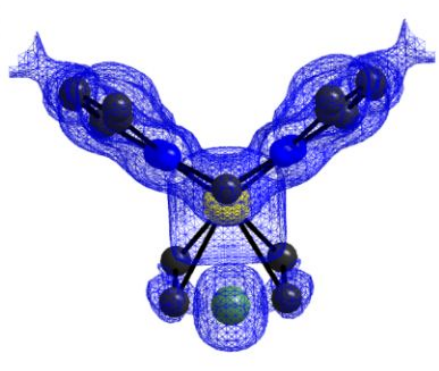

b)

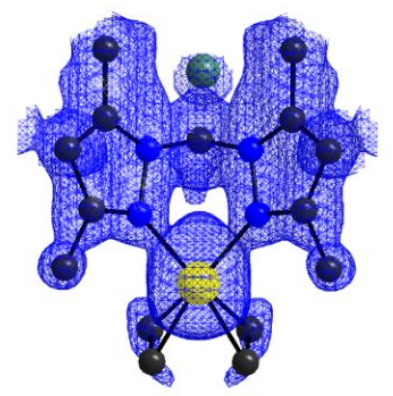

d)

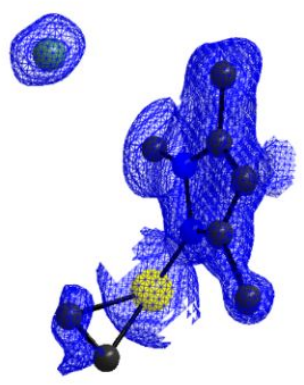

Figure S5.4.5: (a) A perspective view of the chelated $\mathrm{Rh}(\mathrm{I})$ complex in 1.ETH-Cl and the overlaid electron density map as viewed from the (b) front, (c) top and (d) side of the complex.

a)

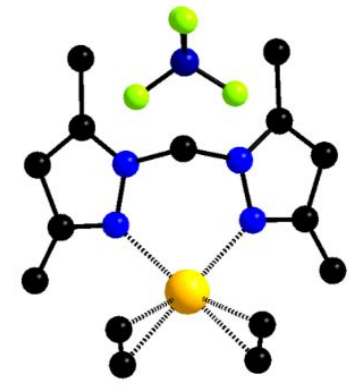

c)

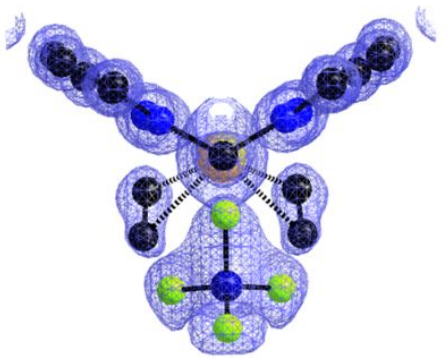

b)

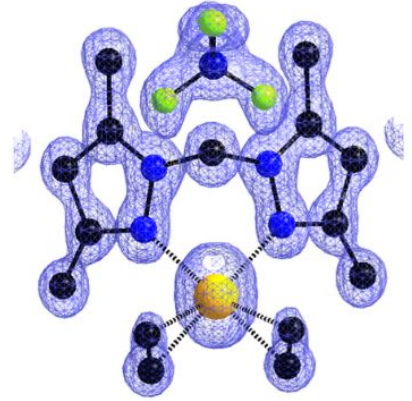

d)

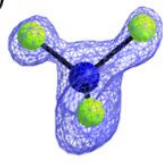

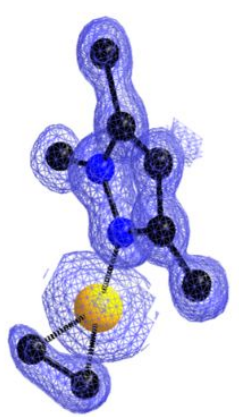

Figure S5.4.6: (a) A perspective view of the chelated $\mathrm{Rh}(\mathrm{I})$ complex in 1.ETH-BF ${ }_{4}$ and the overlaid electron density map as viewed from the (b) front, (c) top and (d) side of the complex. 
a)

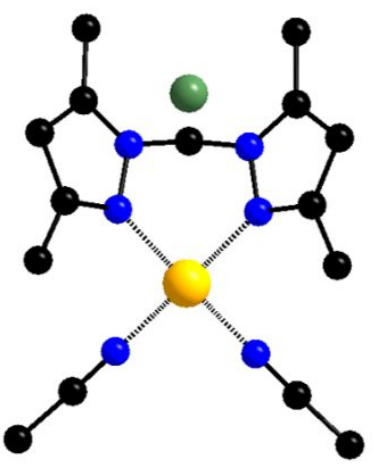

c)

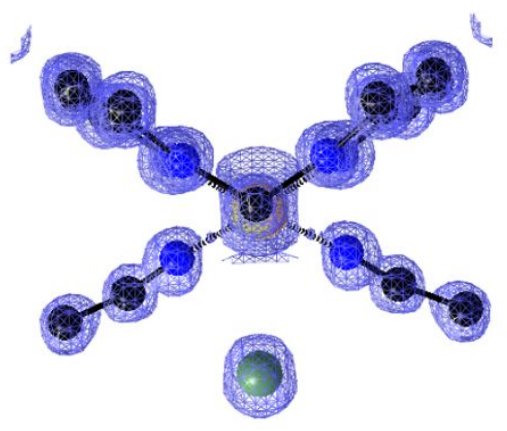

b)

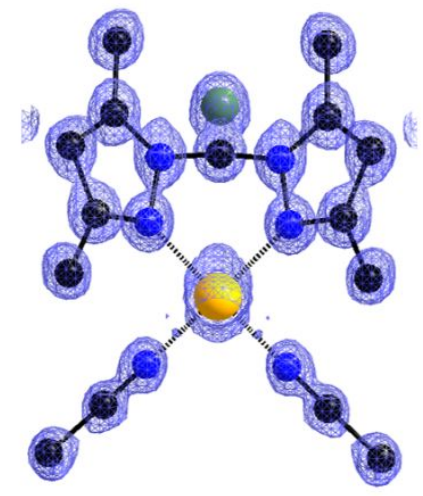

d)

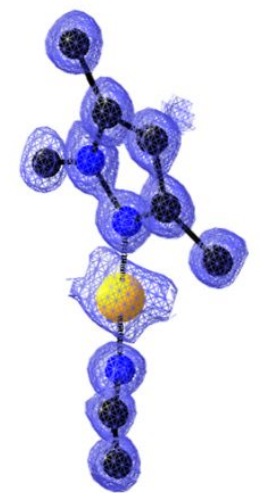

Figure S5.4.7: (a) A perspective view of the chelated $\mathrm{Rh}(\mathrm{I})$ complex in 1.[Rh( $\left.\mathrm{MeCN})_{2}\right] \mathrm{Cl}$ and the overlaid electron density map as viewed from the (b) front, (c) top and (d) side of the complex. 
5.5 Tables of X-ray crystallography data collection and refinement parameters

Table S2. Crystallographic data collection and refinement parameters for the metalated forms of $\mathbf{1}$.

\begin{tabular}{|c|c|c|c|}
\hline Sample & $1 \cdot[\mathrm{Rh}(\mathrm{NBD})]\left[\mathrm{Rh}(\mathrm{NBD}) \mathrm{Cl}_{2}\right]$ & $1 \cdot N B D-C l$ & $1 \cdot \mathrm{NBD}^{-\mathrm{BF}_{4}}$ \\
\hline \multicolumn{4}{|l|}{ Crystallographic Parameter } \\
\hline Formula & $\mathrm{C}_{104} \mathrm{H}_{104.5} \mathrm{Cl}_{2} \mathrm{Mn}_{3} \mathrm{~N}_{19.5} \mathrm{O}_{12} \mathrm{Rh}_{2}$ & $\mathrm{C}_{98.5} \mathrm{H}_{140} \mathrm{ClMn}{ }_{3} \mathrm{~N}_{12} \mathrm{O}_{28.5} \mathrm{Rh}$ & $\mathrm{C}_{91.75} \mathrm{H}_{126.25} \mathrm{BF}_{4} \mathrm{Mn}_{3} \mathrm{~N}_{12} \mathrm{O}_{27.25} \mathrm{Rh}$ \\
\hline FW & 2261 & 2251.40 & 2187.83 \\
\hline $\mathrm{T}, \mathrm{K}$ & $100(2)$ & $100(2)$ & $100(2)$ \\
\hline Wavelength, $\AA$ & Synchrotron (0.71073) & Synchrotron $(\lambda=0.71073)$ & Synchrotron $(\lambda=0.71073)$ \\
\hline Crystal system, space group & Monoclinic $P 2_{1} / m$ & Monoclinic $P 2_{1} / c$ & Monoclinic $P 2_{1} / c$ \\
\hline $\mathrm{Z}$ & 2 & 4 & 4 \\
\hline$a, \AA$ & $12.336(3)$ & $12.453(3)$ & $12.462(3)$ \\
\hline b, $\AA$ & $33.362(7)$ & $33.266(7)$ & $34.572(7)$ \\
\hline$c, \AA$ & $13.082(3)$ & $25.637(5)$ & $25.460(5)$ \\
\hline$\alpha^{\circ}$ & 90 & 90 & 90 \\
\hline$\beta,{ }^{\circ}$ & $95.42(3)$ & $96.44(3)$ & $98.63(3)$ \\
\hline$\gamma^{\circ}$ & 90 & 90 & 90 \\
\hline$V, \AA^{3}$ & $5359.9(19)$ & $10553(4)$ & $10845(4)$ \\
\hline$d_{\text {calc, }}, \mathrm{g} / \mathrm{cm}^{3}$ & 1.401 & 1.417 & 1.340 \\
\hline Absorption coefficient, $\mathrm{mm}^{-1}$ & 0.762 & 0.611 & 0.572 \\
\hline$F(000)$ & 2320.0 & 4720 & 4559.0 \\
\hline Crystal size, $\mathrm{mm}^{3}$ & $0.3 \times 0.15 \times 0.06$ & $0.2 \times 0.11 \times 0.04$ & $0.25 \times 0.13 \times 0.04$ \\
\hline $2 \theta$ range for data collection & 2.442 to 64.242 & 2.014 to 63.75 & 2.002 to 63.698 \\
\hline Index range & $-15 \leq h \leq 15,-44 \leq k \leq 44,-18 \leq 1 \leq 18$ & $-18 \leq h \leq 18,-49 \leq k \leq 49,-35 \leq 1 \leq 35$ & $-18 \leq h \leq 18,-51 \leq k \leq 51,-33 \leq 1 \leq 33$ \\
\hline Reflections collected & 94565 & 194532 & 197727 \\
\hline Independent reflections & $14404\left[R_{\text {int }}=0.0400, R_{\text {sigma }}=0.0229\right]$ & $29921\left[R_{\text {int }}=0.1146, R_{\text {sigma }}=0.0844\right]$ & $30418\left[R_{\text {int }}=0.0610, R_{\text {sigma }}=0.0337\right]$ \\
\hline Data/restraints/parameters & $14404 / 84 / 658$ & $29921 / 113 / 1022$ & $30418 / 35 / 1368$ \\
\hline GOF on $F^{2}$ & 1.025 & 1.150 & 1.147 \\
\hline Largest diff. peak and hole, $\mathrm{e}^{-3}$ & $3.96 /-3.67$ & $2.22 /-2.95$ & $2.10 /-1.30$ \\
\hline$R_{1},[\mid>2 \sigma(I)]$ & 0.0948 & 0.1240 & 0.0719 \\
\hline$w \mathrm{R}_{2}$, all data & 0.2830 & 0.3722 & 0.2124 \\
\hline CCDC Number & 2003248 & 2003247 & 2003249 \\
\hline
\end{tabular}


Table S3. Crystallographic data collection and refinement parameters for the metalated forms of $\mathbf{1}$.

\begin{tabular}{|c|c|c|c|}
\hline Sample & $1 \cdot\left[\mathrm{Rh}\left(\mathrm{C}_{2} \mathrm{H}_{4}\right)_{2}\right]\left[\mathrm{Rh}\left(\mathrm{CH}_{2} \mathrm{CH}_{2}\right)_{2} \mathrm{Cl}_{2}\right]$ & 1.ETH-Cl & $1 \cdot \mathrm{ETH}^{-\mathrm{BF}_{4}}$ \\
\hline \multicolumn{4}{|l|}{ Crystallographic Parameter } \\
\hline Formula & $\mathrm{C}_{105} \mathrm{H}_{152} \mathrm{Cl}_{2} \mathrm{Mn}_{3} \mathrm{~N}_{12} \mathrm{O}_{23} \mathrm{Rh}_{2}$ & $\mathrm{C}_{106.5} \mathrm{H}_{140} \mathrm{ClMn}_{3} \mathrm{~N}_{12} \mathrm{O}_{12} \mathrm{Rh}$ & $\mathrm{C}_{79} \mathrm{H}_{74} \mathrm{BF}_{4} \mathrm{Mn}_{3} \mathrm{~N}_{12} \mathrm{O}_{12} \mathrm{Rh}$ \\
\hline FW & 2391.92 & 2083.48 & 2134.84 \\
\hline $\mathrm{T}, \mathrm{K}$ & $100(2)$ & $100(2)$ & $100(2)$ \\
\hline Wavelength, $\AA$ & Synchrotron $(\lambda=0.71073)$ & Synchrotron $(\lambda=0.71073)$ & Synchrotron $(\lambda=0.71073)$ \\
\hline Crystal system, space group & Monoclinic $P 2_{1} / \mathrm{m}$ & Monoclinic $P 2_{1} / m$ & Monoclinic $P 2_{1} / m$ \\
\hline $\mathrm{Z}$ & 2 & 2 & 2 \\
\hline$a, \AA$ & $12.362(3)$ & $12.288(3)$ & $12.239(2)$ \\
\hline$b, \AA$ & $33.404(7)$ & $32.624(7)$ & $34.061(7)$ \\
\hline c, $\AA$ & $13.013(3)$ & $12.928(3)$ & $12.913(3)$ \\
\hline$\alpha^{\circ}$ & 90 & 90 & 90 \\
\hline$\beta$, & $97.03(3)$ & $95.46(3)$ & $99.45(3)$ \\
\hline$\gamma^{\circ}$ & 90 & 90 & 90 \\
\hline$V, \AA^{3}$ & $5333.2(19)$ & $5159.1(18)$ & $5310.1(19)$ \\
\hline$d_{\text {calc, }}, \mathrm{g} / \mathrm{cm}^{3}$ & 1.489 & 1.341 & 1.335 \\
\hline Absorption coefficient, $\mathrm{mm}^{-1}$ & 0.776 & 0.607 & 0.572 \\
\hline$F(000)$ & 2498.0 & 2192.0 & 2240.0 \\
\hline Crystal size, $\mathrm{mm}^{3}$ & $0.4 \times 0.25 \times 0.05$ & $0.4 \times 0.25 \times 0.06$ & $0.40 \times 0.20 \times 0.05$ \\
\hline Theta range for data collection & 2.438 to 58.41 & 2.496 to 64.324 & 2.392 to 56.37 \\
\hline Index range & $-14 \leq h \leq 14,-39 \leq k \leq 39,-17 \leq \mathrm{I} \leq 17$ & $-16 \leq h \leq 16,-44 \leq k \leq 44,-16 \leq \mathrm{I} \leq 18$ & $-14 \leq h \leq 15,-42 \leq k \leq 42,-16 \leq 1 \leq 15$ \\
\hline Reflections collected & 55421 & 51436 & 52134 \\
\hline Independent reflections & $10199\left[R_{\text {int }}=0.0729, R_{\text {sigma }}=0.0498\right]$ & $11410\left[R_{\text {int }}=0.0973, R_{\text {sigma }}=0.0949\right]$ & $10266\left[R_{\text {int }}=0.0616, R_{\text {sigma }}=0.0495\right]$ \\
\hline Data/restraints/parameters & $10199 / 58 / 566$ & $11410 / 110 / 536$ & $10266 / 5 / 526$ \\
\hline GOF on $\mathrm{F}^{2}$ & 1.755 & 0.959 & 1.120 \\
\hline Largest diff. peak and hole, e. $\AA^{-3}$ & $1.91 /-3.13$ & $1.11 /-0.94$ & $1.17 /-0.91$ \\
\hline$R_{1},[\mathrm{I}>2 \sigma(\mathrm{I})]$ & 0.1840 & 0.1497 & 0.0975 \\
\hline$w \mathrm{R}_{2}$, all data & 0.4706 & 0.3869 & 0.3240 \\
\hline CCDC Number & 2003252 & 2003251 & 2003253 \\
\hline
\end{tabular}


Table S4. Crystallographic data collection and refinement parameters for the metalated forms of $\mathbf{1}$.

\begin{tabular}{|c|c|}
\hline Sample & $1 \cdot\left[\mathrm{Rh}(\mathrm{MeCN})_{2}\right] \mathrm{Cl}$ \\
\hline \multicolumn{2}{|l|}{ Crystallographic Parameter } \\
\hline Formula & $\mathrm{C}_{109} \mathrm{H}_{132} \mathrm{ClMn}_{3} \mathrm{~N}_{14} \mathrm{O}_{19.5} \mathrm{Rh}$ \\
\hline FW & 2253.46 \\
\hline $\mathrm{T}, \mathrm{K}$ & 100(2) \\
\hline Wavelength, $\AA$ & Synchrotron $(\lambda=0.71073)$ \\
\hline Crystal system, space group & Monoclinic $P 2_{1} / m$ \\
\hline Z & 2 \\
\hline$a, \AA$ & $12.329(3)$ \\
\hline$b, \AA$ & $32.790(7)$ \\
\hline$c, \AA$ & $13.037(3)$ \\
\hline$\alpha^{\circ}$ & 90 \\
\hline$\beta$, & $94.16(3)$ \\
\hline$\gamma^{\circ}$ & 90 \\
\hline$V, \AA^{3}$ & $5256.6(18)$ \\
\hline$d_{\text {calc, }} g / \mathrm{cm}^{3}$ & 1.424 \\
\hline Absorption coefficient, $\mathrm{mm}^{-1}$ & 0.608 \\
\hline$F(000)$ & 2354.0 \\
\hline Crystal size, $\mathrm{mm}^{3}$ & $0.22 \times 0.13 \times 0.03$ \\
\hline Theta range for data collection & 2.484 to 63.618 \\
\hline Index range & $-15 \leq h \leq 15,-43 \leq k \leq 43,-17 \leq \mathrm{I} \leq 17$ \\
\hline Reflections collected & 95799 \\
\hline Independent reflections & $14009\left[R_{\text {int }}=0.0501, R_{\text {sigma }}=0.0302\right]$ \\
\hline Data/restraints/parameters & $14009 / 0 / 554$ \\
\hline GOF on $F^{2}$ & 1.044 \\
\hline Largest diff. peak and hole, e $\cdot \AA^{-3}$ & $3.47 /-2.04$ \\
\hline$R_{1},[\mid>2 \sigma(I)]$ & 0.1009 \\
\hline$w \mathrm{R}_{2}$, all data & 0.2896 \\
\hline CCDC Number & 2003250 \\
\hline
\end{tabular}




\section{SI6.0 Isotherm data}

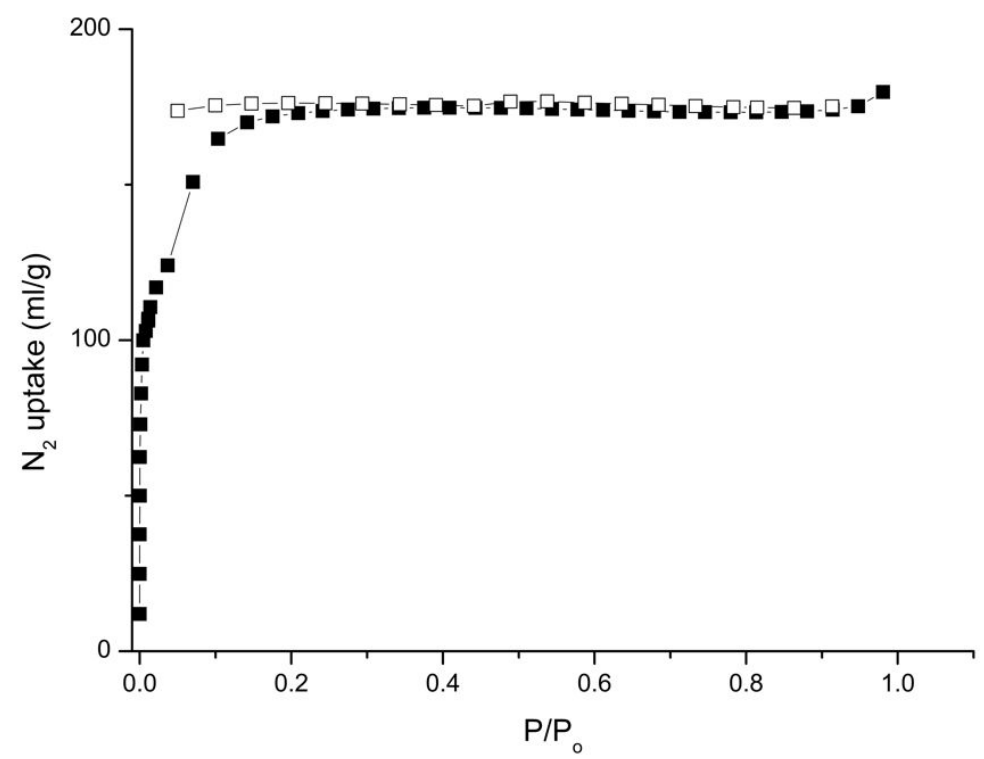

Figure SI 6.1: $\mathrm{N}_{2}$ isotherm data collected on 1.NP at 77K, after activation from dry acetone at $80^{\circ} \mathrm{C}$ for 20 hr. Black squares represent adsorption, open squares represent desorption.

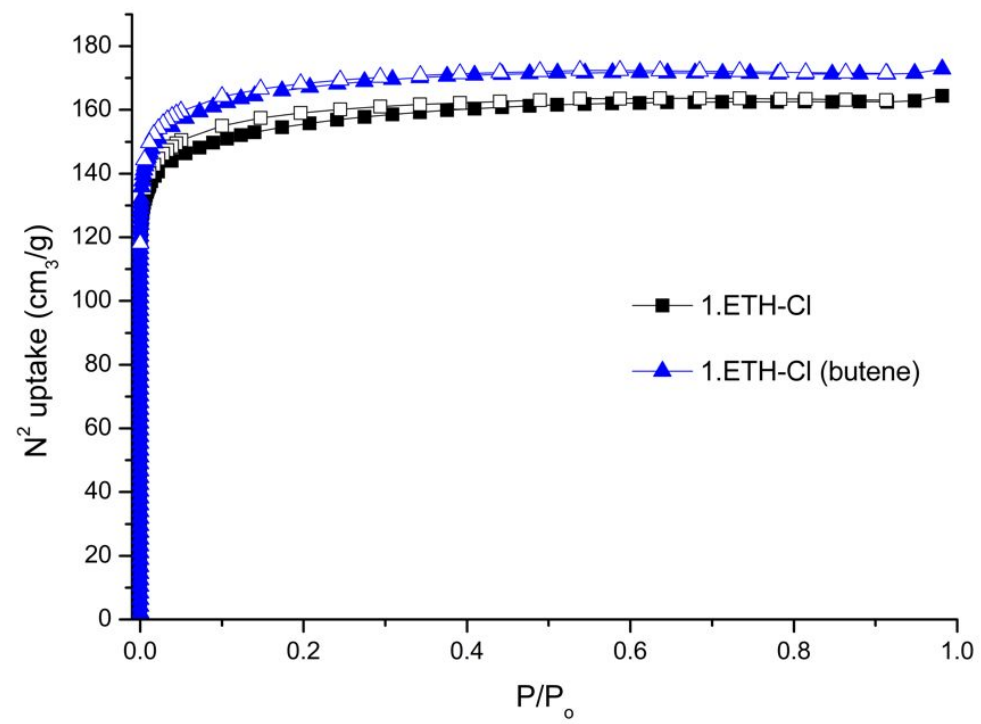

Figure SI 6.2: $\mathrm{N}_{2}$ isotherm data collected on 1.ETH-Cl at 77K, after activation from dry pentane at RT for 2 $\mathrm{hr}$ (black squares) and following reaction with 1-butene for $3 \mathrm{hr}$ (blue triangles). Coloured squares/triangles represent adsorption, open squares/triangles represent desorption. 


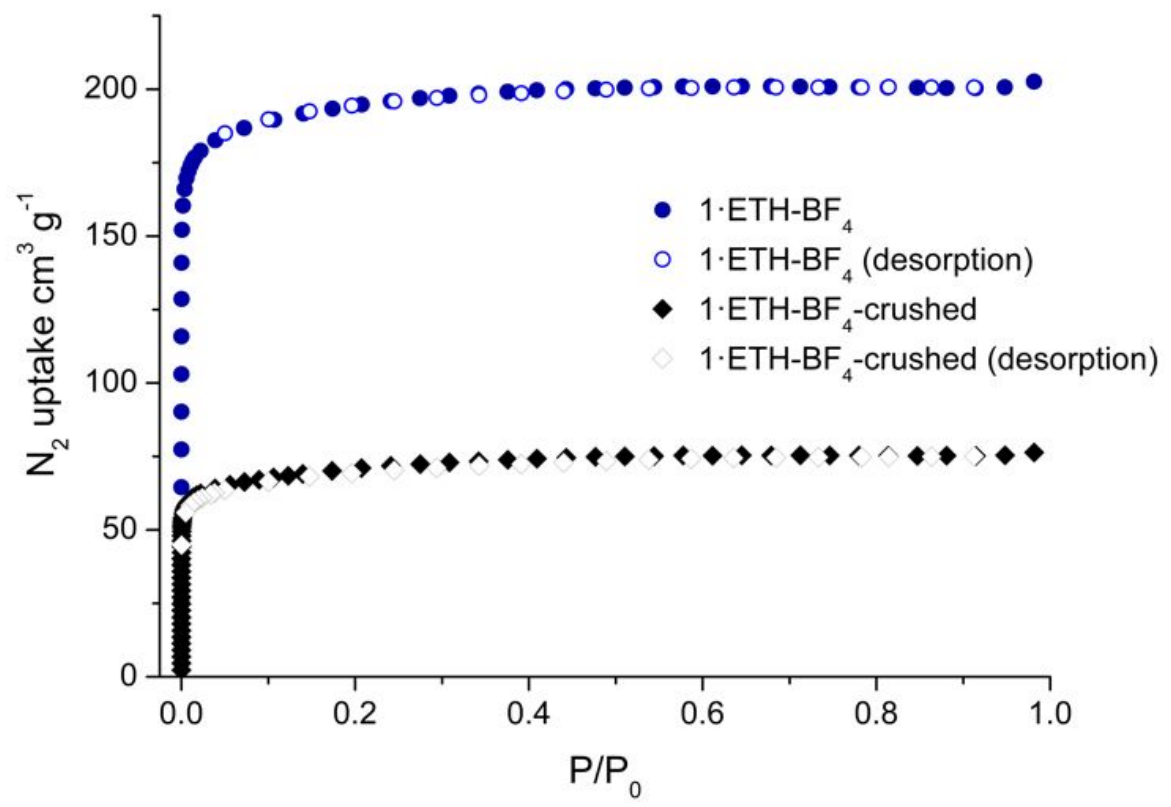

Figure SI 6.3: isotherms collected at $77 \mathrm{~K}$ for $1 \cdot \mathrm{ETH}^{-\mathrm{BF}_{4}}$ and 1.ETH-BF${ }_{4}$-crushed, displaying the significant loss of surface area in the crushed sample. 
SI7.0 Nuclear Magnetic Resonance (NMR) data

SI7.1 Time resolved NMR data for ethylene hydrogenation

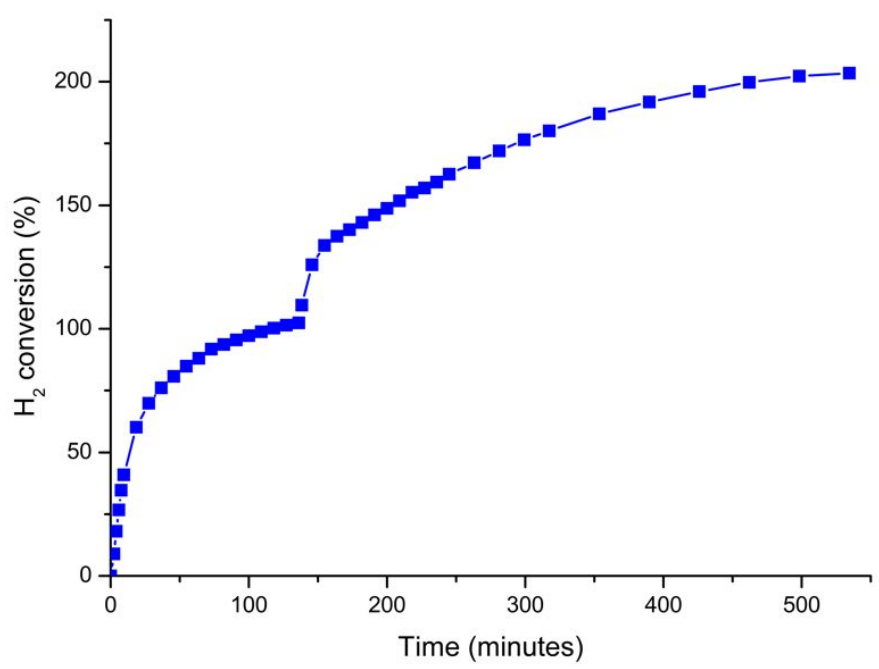

Figure SI 7.1.1: The hydrogenation of ethylene over 1.NP at $46^{\circ} \mathrm{C}$ proceeds rapidly in the first cycle but slows down significantly in the second cycle.

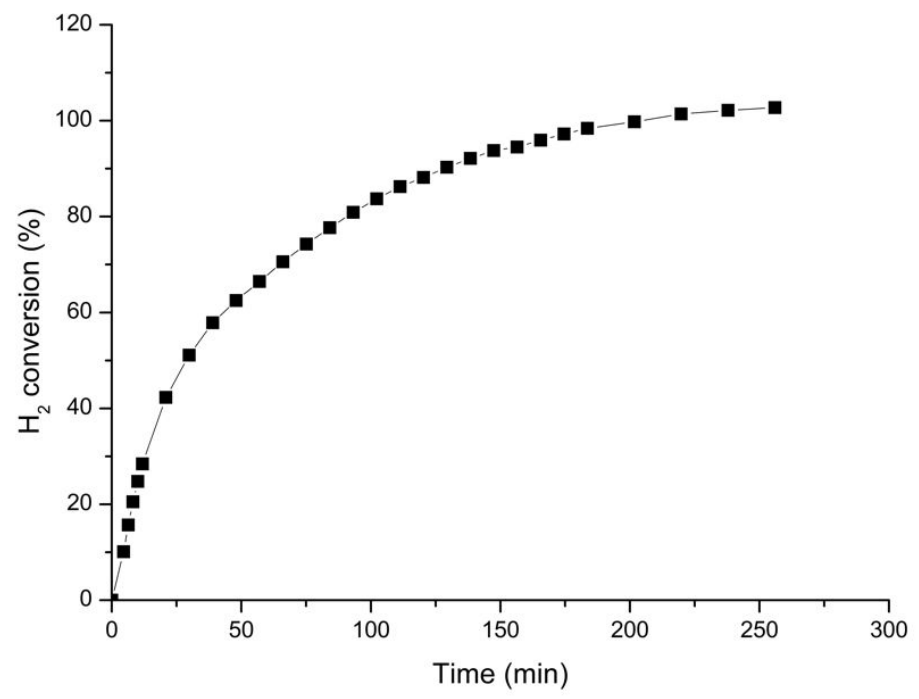

Figure SI 7.1.2: The hydrogenation of ethene over a crushed sample of 1.ETH-BF 4 at $46^{\circ} \mathrm{C}$. 
SI7.2 Time resolved NMR data for butene isomerisation

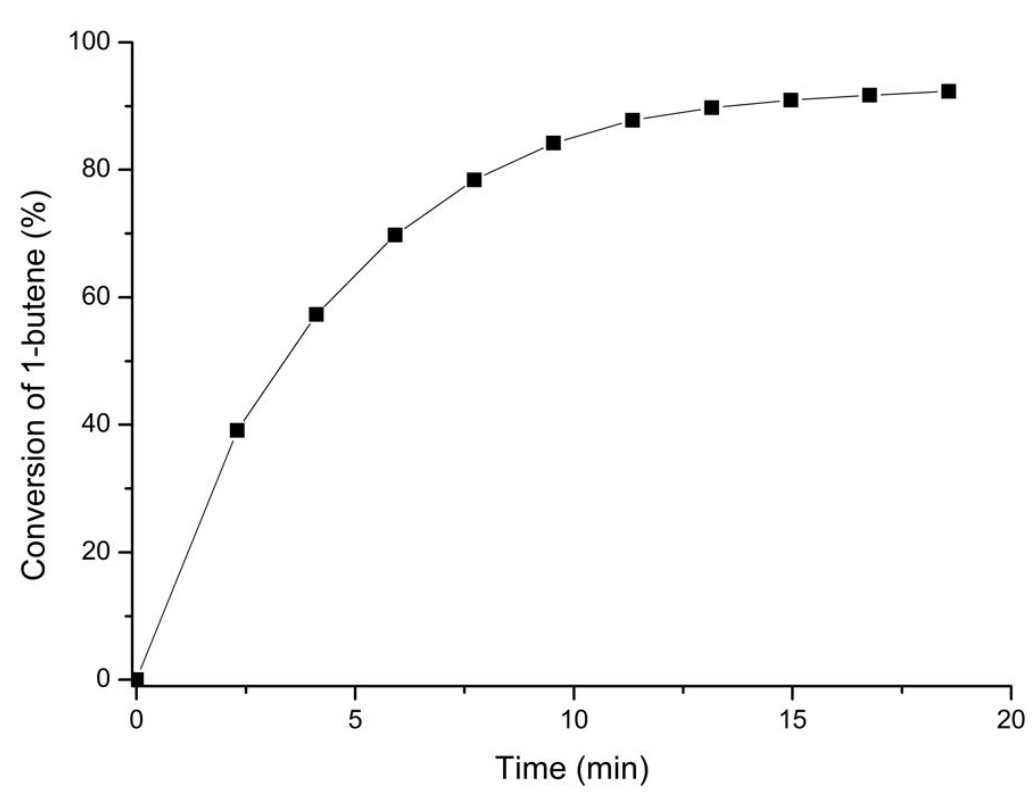

Figure SI 7.2.1: Butene isomerisation catalysed by a crushed sample of $1 \cdot \mathrm{ETH}^{-\mathrm{BF}_{4}}$ as determined by gasphase NMR. 
S7.3 Sample composition analysis using a $\mathrm{CO} / \mathrm{CH}_{4}$ probe

Samples of 1.ETH-BF 4 and 1.ETH-Cl were activated in a high-pressure NORELL NMR tube using the same protocol described in the experimental. Following activation, the NMR tube was dosed with a mixture of 1 bar of $\mathrm{CH}_{4}$ and 1 bar of $\mathrm{CO}$. The tube was sealed and transferred to a Varian Gemini $600 \mathrm{MHz} \mathrm{NMR}$.

Exposure to $\mathrm{CO} / \mathrm{CH}_{4}$ results in an instantaneous color change form yellow to off-white, which, in conjunction with the presence of $\mathrm{CO}$ stretching bands in the IR spectrum of the MOF crystals, verified that 1. $\left[\mathrm{Rh}(\mathrm{CO})_{2}\right] \mathrm{BF}_{4}$ and 1. $\left[\mathrm{Rh}(\mathrm{CO})_{2}\right] \mathrm{Cl}$ were formed (SI Figure 7.3.2-3). Gas-phase NMR spectra of the headspace in the NMR tube revealed the amount of ethylene displaced from the $\mathrm{Rh}(\mathrm{I})$ centre (SI Figure 7.3.45) via integration of the ethylene and methane signals; the result is consistent with retention of $\sim 90 \%$ for both samples.

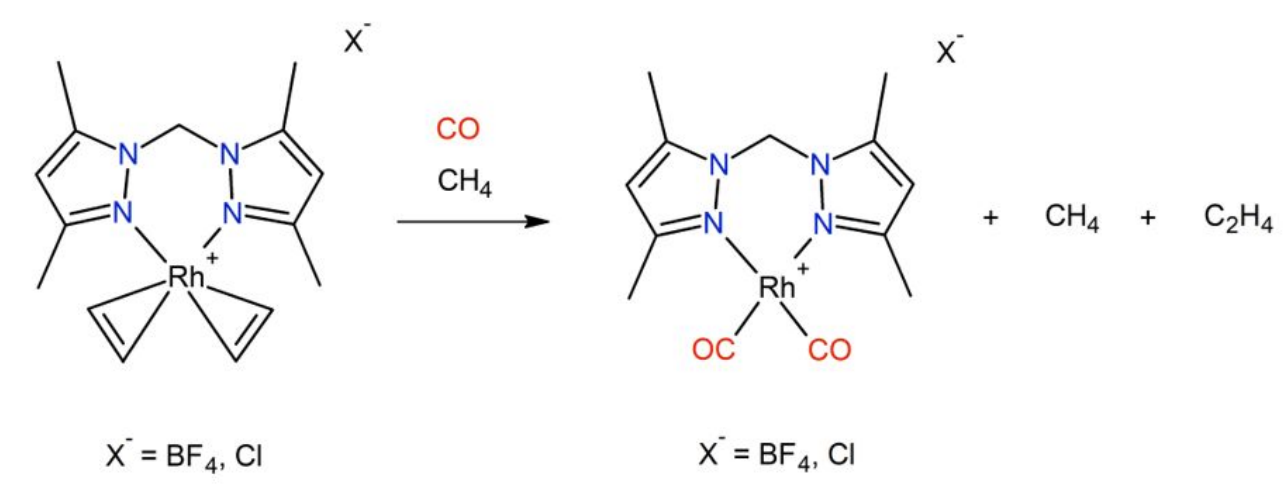

Figure SI 7.3.1: Reaction scheme showing the displacement of the ethylene from the Rh(I) center in 1.ETH$\mathrm{BF}_{4}$ or $1 \cdot \mathrm{ETH}-\mathrm{Cl}$ in presence of $\mathrm{CO} / \mathrm{CH}_{4}$. 


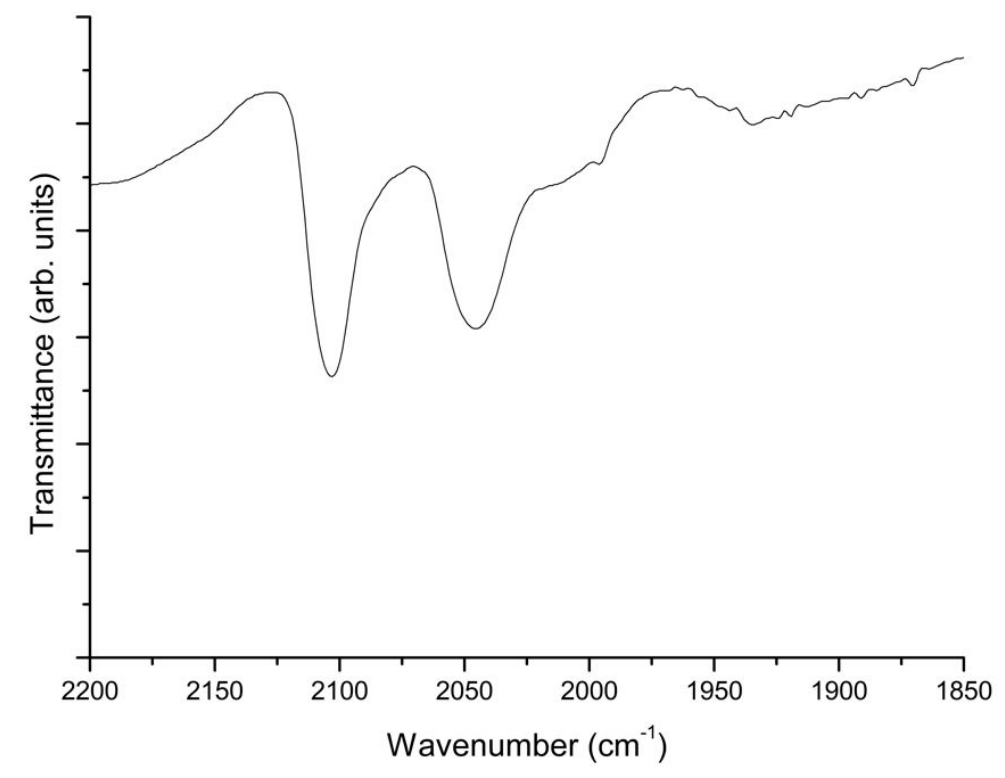

Figure SI 7.3.2: Infra-red spectrum of 1.ETH- $\mathrm{BF}_{4}$ crystals following exposure to $\mathrm{CO} / \mathrm{CH}_{4}$, displaying the strong $\mathrm{CO}$ stretches corresponding to the formation of $1 \cdot\left[\mathrm{Rh}(\mathrm{CO})_{2}\right] \mathrm{BF}_{4}$.

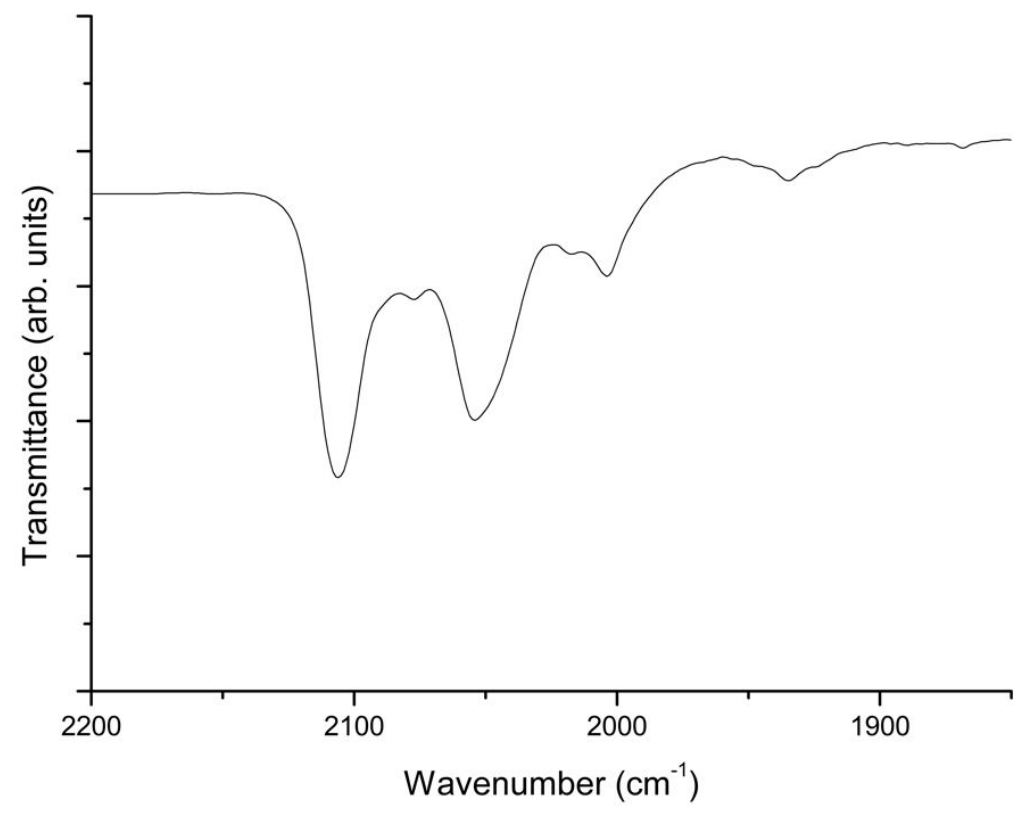

Figure SI 7.3.3: Infra-red spectrum of 1-ETH-Cl crystals following exposure to $\mathrm{CO} / \mathrm{CH}_{4}$, displaying the strong $\mathrm{CO}$ stretches corresponding to the formation of $1 \cdot\left[\mathrm{Rh}(\mathrm{CO})_{2}\right] \mathrm{Cl}$. 


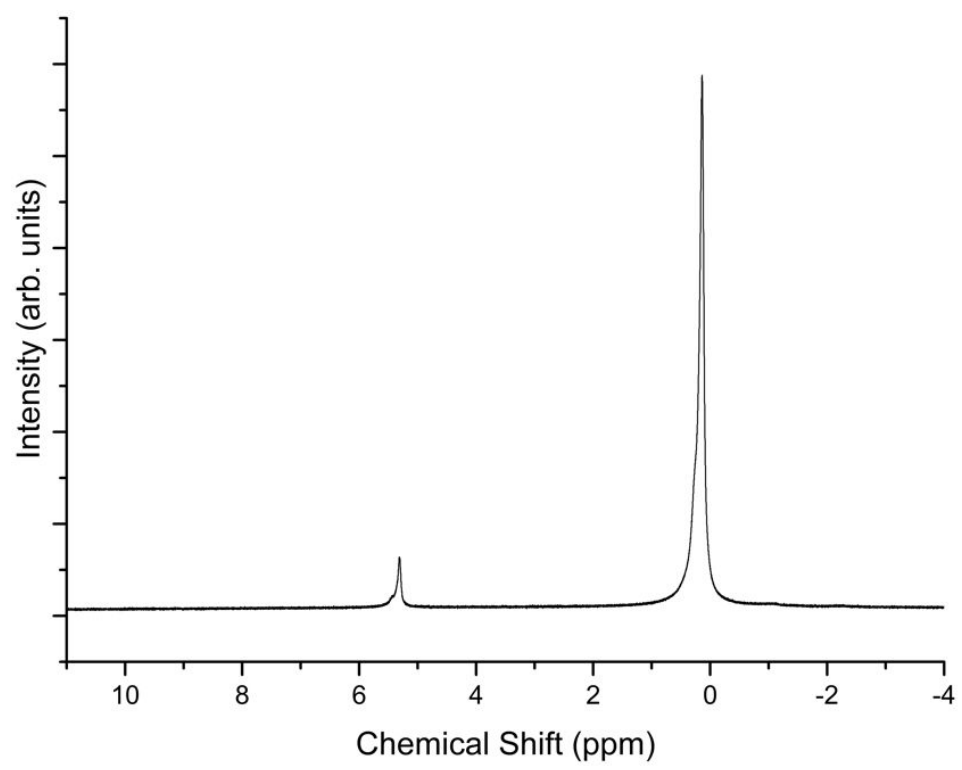

Figure SI 7.3.4: ${ }^{1} \mathrm{H}$ NMR spectrum obtained from the headspace of an NMR tube containing 1.ETH-BF crystals following exposure to $\mathrm{CO} / \mathrm{CH}_{4}$, displaying the ethylene $(5.31 \mathrm{ppm})$ and methane $(0.14 \mathrm{ppm})$ resonances.

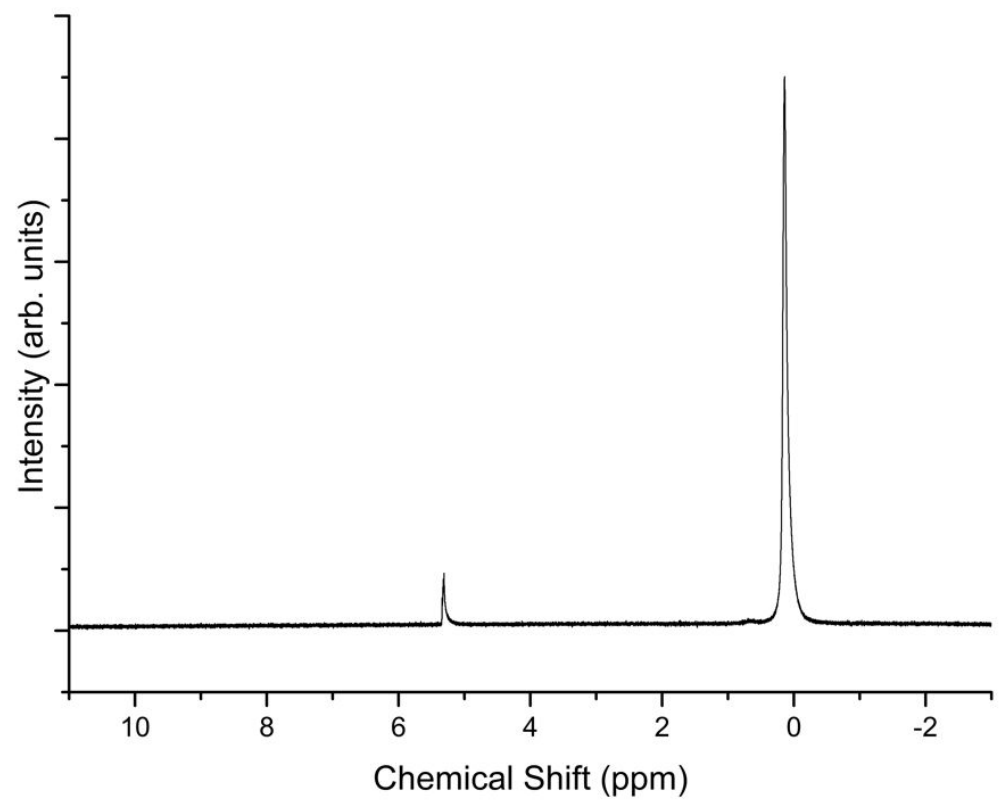

Figure SI 7.3.5: ${ }^{1} \mathrm{H}$ NMR spectrum obtained from the headspace of an NMR tube containing 1.ETH-Cl crystals following exposure to $\mathrm{CO} / \mathrm{CH}_{4}$, displaying the ethylene $(5.31 \mathrm{ppm})$ and methane $(0.14 \mathrm{ppm})$ resonances. 
SI 7.4 Analysis of 2-butene isomers generated under gas-phase isomerisation

The ratio of cis- and trans-2-butene was determined using ${ }^{1} \mathrm{H}$ NMR of the gaseous products dissolved in $\mathrm{CDCl}_{3}$. To achieve this and avoid any paramagnetic effects from the $\mathrm{Mn}$ (II) MOF, the gas-phase butene isomerisation reaction was conducted in an NMR tube as reported in the experimental section. A second NMR tube fitted with a young tap was placed under vacuum and cooled in an acetone/dry ice bath. The second tube was sealed and connected to the tap assembly of the first via a short piece of rubber tubing. The tubes were opened to each-other, such that some of the gaseous butenes in the first would enter the second tube and condense. $\mathrm{CDCl}_{3}$ was added to the second tube to dissolve the condensed gas. ${ }^{1} \mathrm{H} \mathrm{NMR}$ analysis revealed the presence of an approximately 4:1 ratio of trans:cis 2-butenes, ${ }^{9}$ predominant formation of the trans-isomer is consistent has been previously reported by Weller et al. under similar conditions. ${ }^{10-11}$

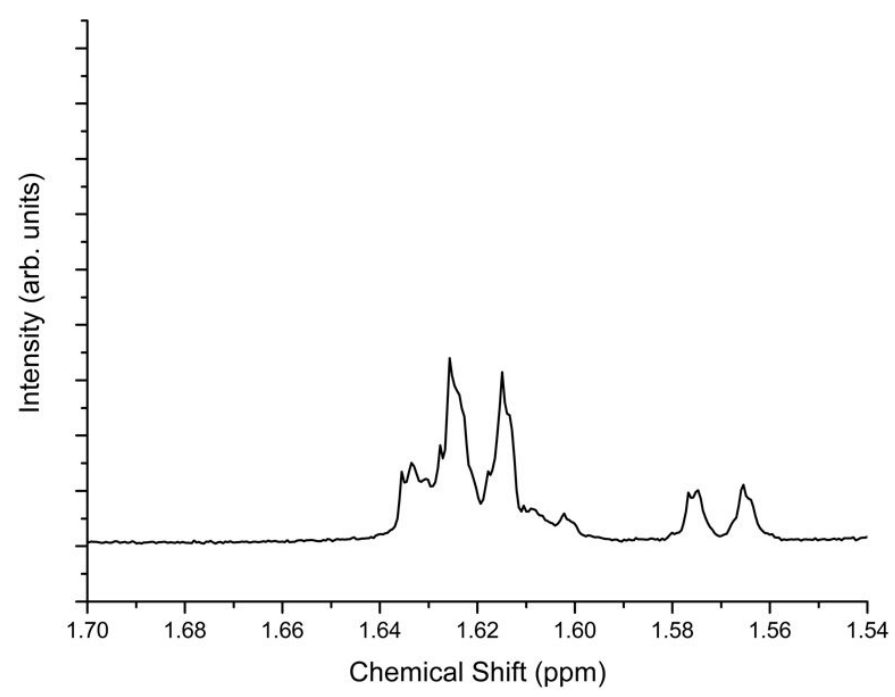

Figure SI 7.4.1: ${ }^{1} \mathrm{H}$ NMR spectrum $\left(\mathrm{CDCl}_{3}\right)$ of condensed gaseous species in the headspace of the NMR tube used for butene isomerisation catalysis, the region of the NMR corresponding to the methyl substituents of cis (1.62ppm) and trans-2-butene (1.57ppm) is shown. 


\section{S18.0 Infrared (IR) Spectroscopy}

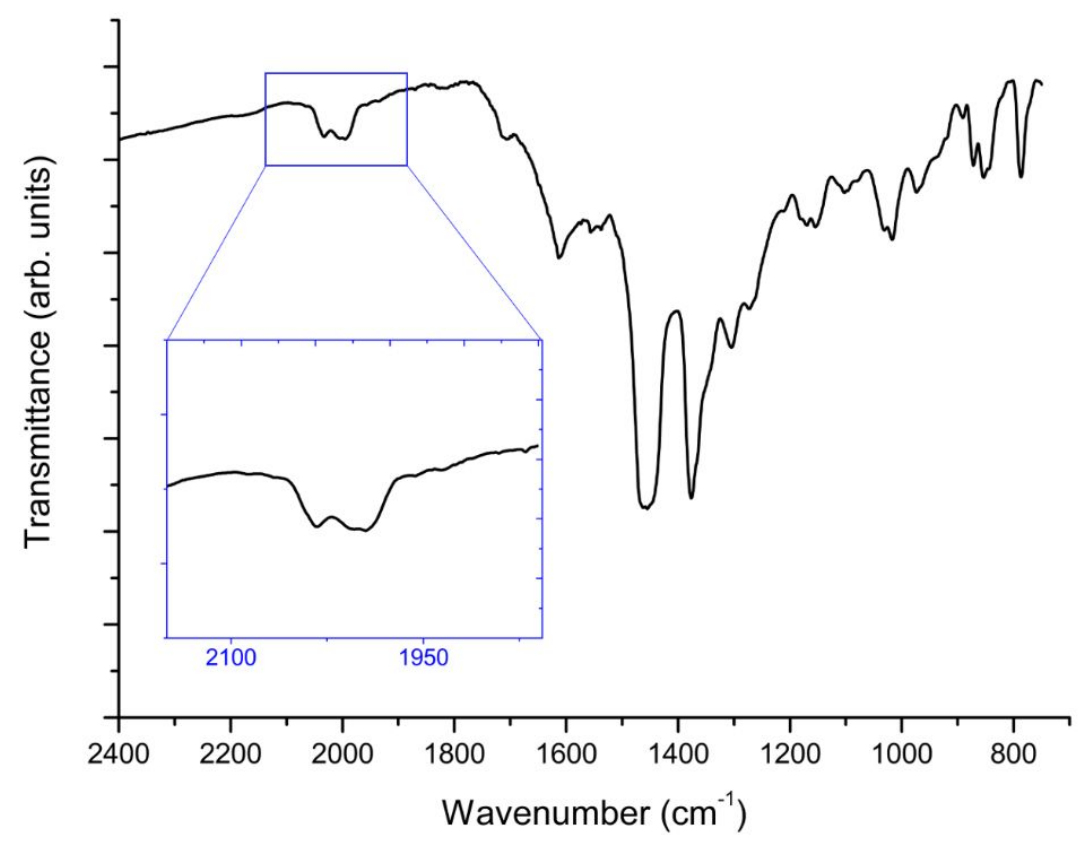

Figure SI 8.1: Infra-red spectrum (nujol) of 1.ETH-Cl crystals following exposure to 1-butene at $46^{\circ} \mathrm{C}$, displaying the weak rhodium hydride stretches observed at 2034 and $2000 \mathrm{~cm}^{-1}$.

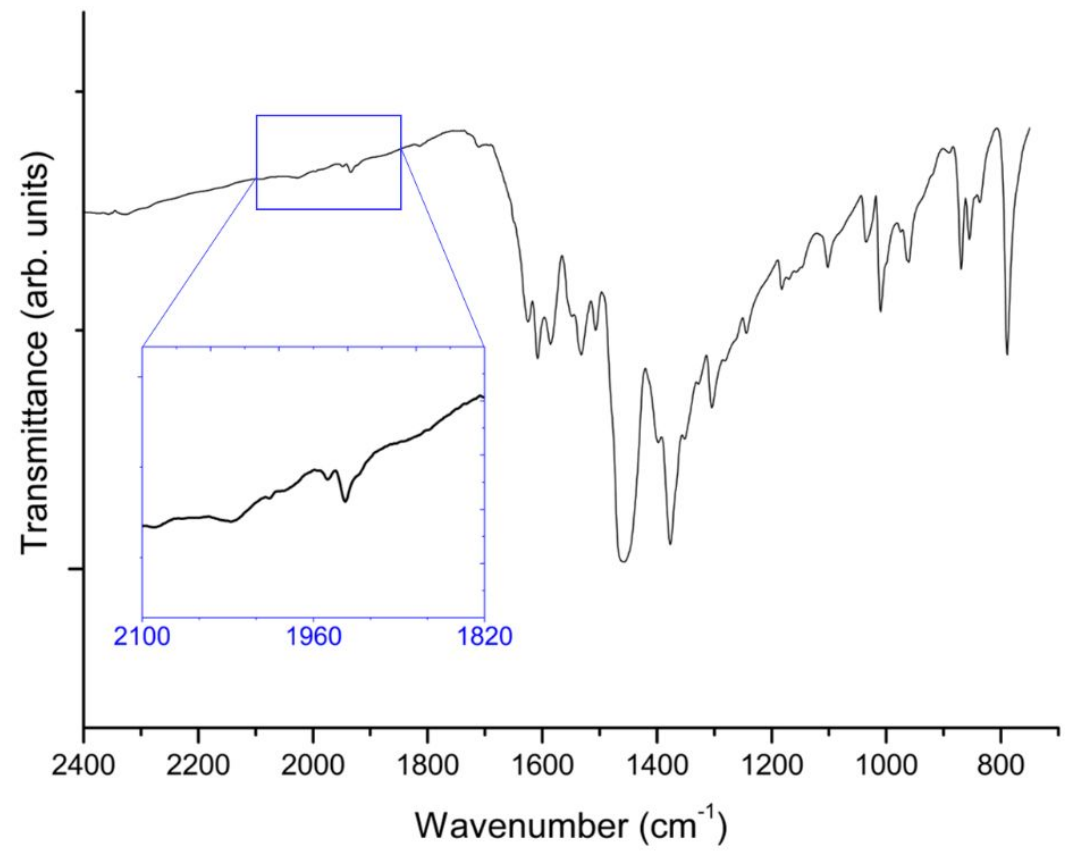

Figure SI 8.2: Infra-red spectrum (nujol) of 1·ETH-Cl crystals following ethylene hydrogenation (1.2 bar ethylene, 0.8 bar $\mathrm{H}_{2}$ ) at $46^{\circ} \mathrm{C}$, displaying the weak rhodium hydride stretches observed at 2026 and 1934 $\mathrm{cm}^{-1}$. 


\section{SI 9.0 High Pressure Reaction Vessel Details}

The high-pressure reactors (Figure SI 9.1) used for post-synthetic metalation of 1 under ethylene were developed in-house. A $20 \mathrm{ml}$ high-pressure glass tube from Ace glass Inc. (item 7644-15, 15mm thread) sealed via a threaded PTFE plug was drilled to accommodate a pressure gauge and tap assembly (SI Figure 9.1).

The PTFE solid plug (item 5845-47) with O-RING back seal was modified to add an O-RING front seal (VITON BS010) and a 1/4" diameter hole was bored through the plug such that the tube could be evacuated and filled with an appropriate atmosphere.

A flange screw nut \#15mm Ace Thread with flange diameter $1.5^{\prime \prime}$ x 3/8" thick was 3D printed in PLA and used to modify the 5845-47 PTFE Solid Plug.

A flanged stud was prepared for insertion through the PTFE lid using a 1/4" UNF x 1.5" long 304 Stainless Steel, hexagon head bolt. The bolt head was modified to accommodate the flange (flange diameter 0.669" $x .109 "$ thickness with $2 \times$ flat edges, $15 \mathrm{~mm} \mathrm{~A} / \mathrm{F}$, and $1 / 8$ " hole bored through).

This was assembled by inserting the 5845-47 PTFE solid plug into the 1/4" UNF flanged stud, via the front seal end, and was screwed together by a $1 / 4$ UNF female to $1 / 4$ " NPT, female 304 stainless steel bush adapter, with 2 flat edges, 5/8" A/F.

A Swagelok 1/4" NPT male x 1/4" NPT male stainless-steel hex nipple fitted into bush adapter with PTFE tape, before the 7644-15 glass connector is assembled to 5845-47 PTFE solid plug.

\section{Swagelok fittings used in the assembly are as follows:}

SS-4-HN (Stainless Steel Pipe Fitting, Hex Nipple, 1/4 in. Male NPT)

SS-4-T (Stainless Steel Pipe Fitting, Tee, 1/4 in. Female NPT)

PGI-63B-BG16-LOAX (PGI Series gauge 0-16 bar Lower mount 1/4" male NP)

SS-400-1-4 (SS Swagelok Tube Fitting, Male Connector, 1/4 in. Tube OD x 1/4 in. Male NP)

SS-4P4T (SS Quarter-Turn Instrument Plug Valve, 1/4 in. Swagelok Tube Fitting, 1.6 Cv)

Teflon tape was applied to all Swagelok fittings with NPT male threads before assembly.

The pressure vessel was pressure tested to $80 \mathrm{psi}$ (5.5 bar) with compressed air for 24 hours.

The glass pressure tube was stored in a $120^{\circ} \mathrm{C}$ drying oven between use. 


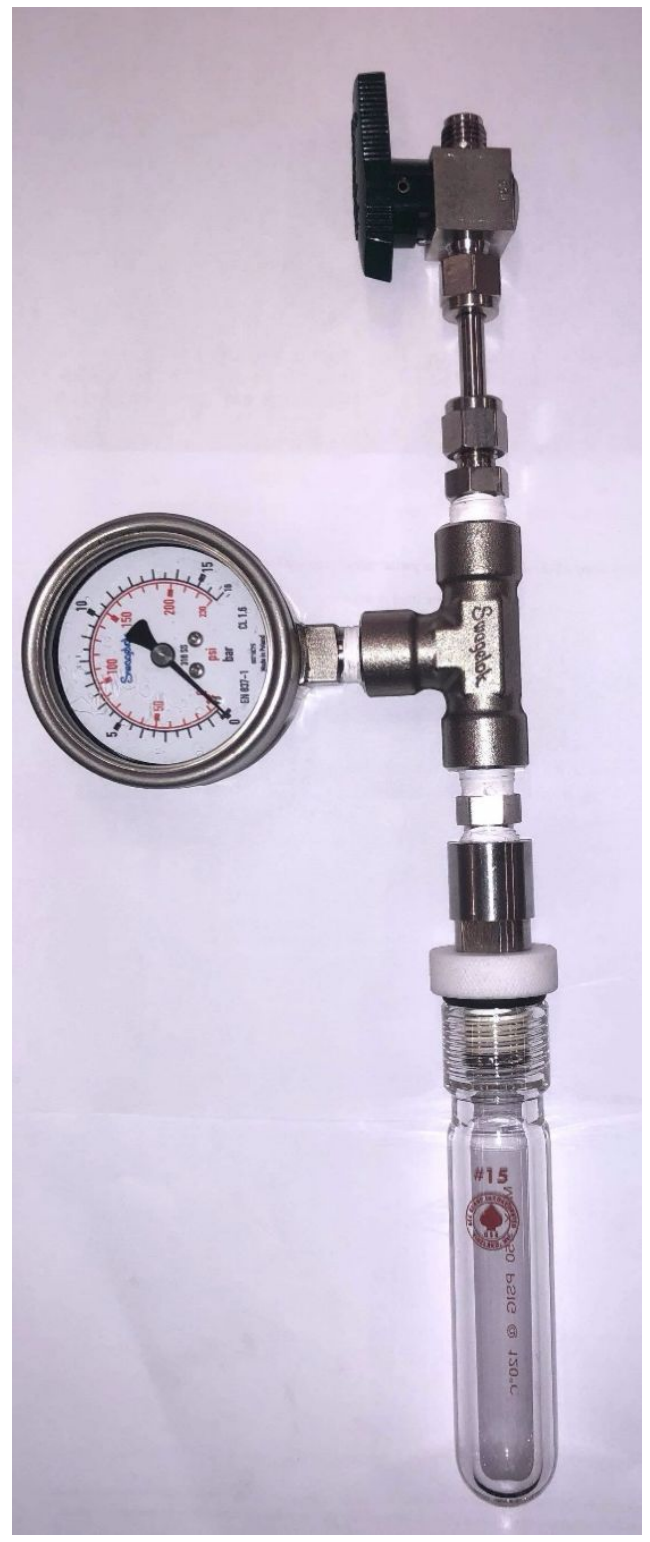

Figure SI 9.1: Glass pressure vessel fitted with a pressure gauge and tap assembly. 


\section{SI 10.0 X-ray Photoelectron Spectroscopy (XPS) Experiments}

XPS spectra were acquired in a custom designed UHV systems equipped with an Omicron EA125 electron analyser and a dual anode $x$-ray source (Omicron DAR 400). The samples were dispersed onto carbon tape under N2 atmosphere and then left to outgas overnight prior to the measurements. Due to the insulating nature of the samples, a flood gun was used to compensate charging effects. The binding energy scale was calibrated used the $C 1$ s spectrum, which was positioned at $284.8 \mathrm{eV}$.
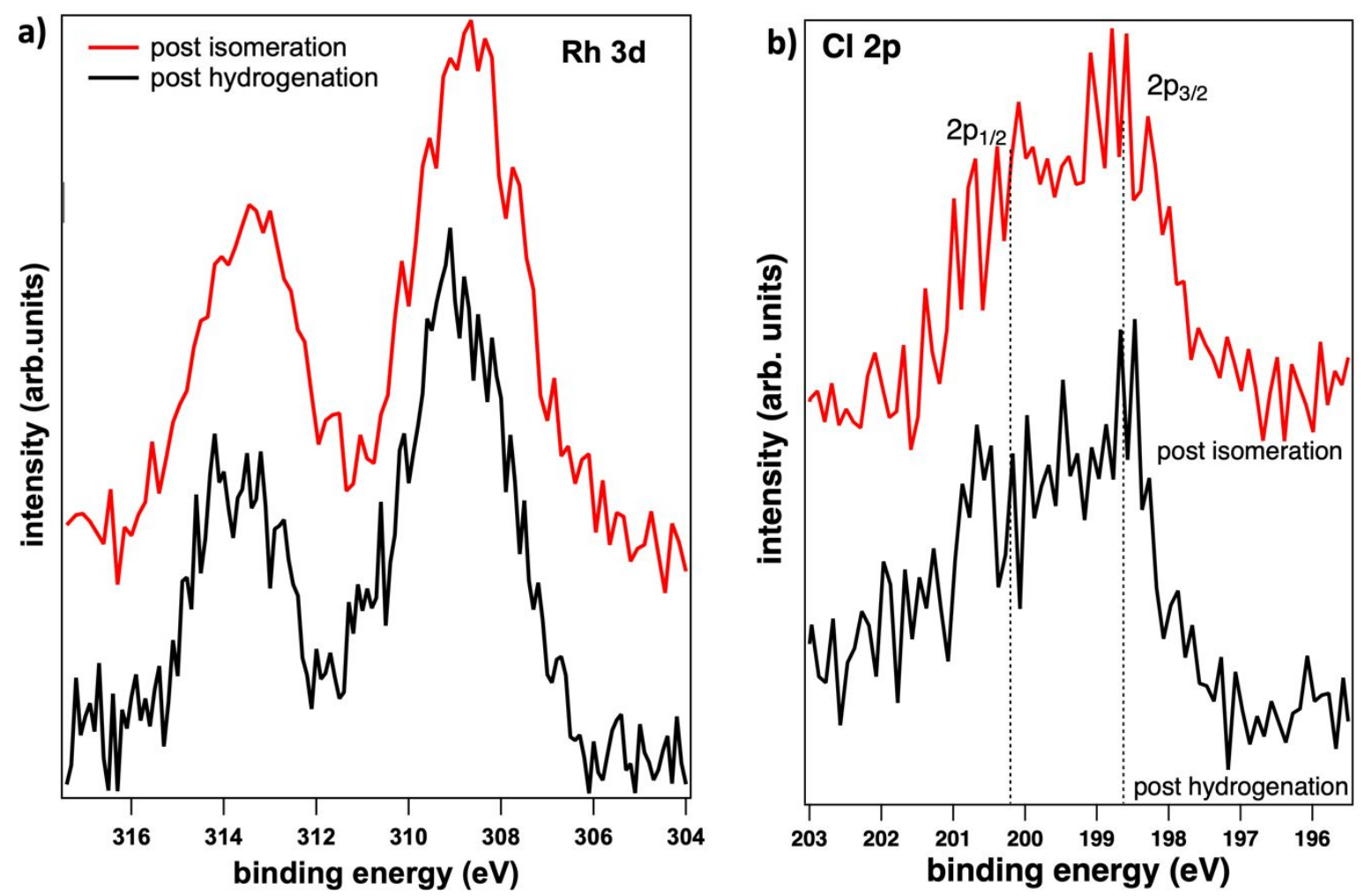

Figure SI 10.1: (a) $\mathrm{Rh} 3 \mathrm{~d}$ and (b) $\mathrm{Cl} 2 \mathrm{p}$ photoemission spectra of 1.ETH-Cl crystals after butene isomerisation (red) and ethylene hydrogenation (black). 


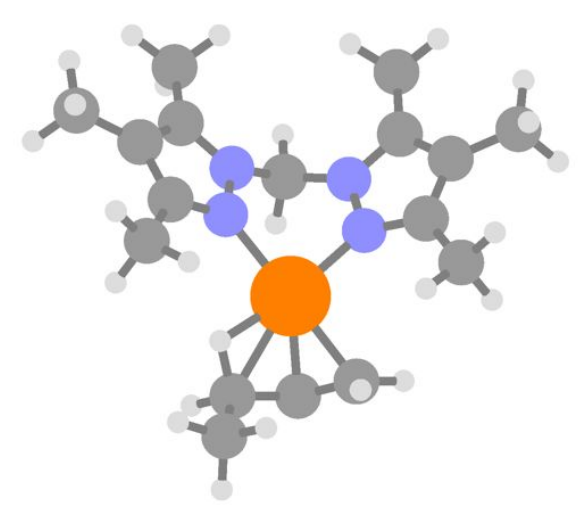

Figure SI 11.1: Structure of the representative Rh complex with bound 1-butene. Rh, orange; C, gray; N, blue; $\mathrm{H}$, white.

Table S5. Relative free energies of the Rh complexes for the proposed mechanism butene isomerization.

\begin{tabular}{ll}
\hline Complex & $\Delta \mathbf{G} / \mathbf{k J ~ m o l}^{-1}$ \\
\hline $\mathrm{I}$ & 4.95 \\
$\mathrm{II}$ & 12.2 \\
$\mathrm{III}$ & 0.00 \\
\hline
\end{tabular}

Table S6. Energy barriers obtained by climbing image nudged elastic band for the Rh complexes.

\begin{tabular}{ll}
\hline Barrier & $\Delta E / \mathrm{kJ} \mathrm{mol}^{-1}$ \\
\hline $\mathrm{I} \rightarrow \mathrm{I}$ & 36.6 \\
$\|\rightarrow\| \mathrm{I}$ & 14.7 \\
\hline
\end{tabular}

Table S7. Relative free energies of the Rh complexes with $\mathrm{Cl}$ present for the proposed mechanism butene isomerization.

\begin{tabular}{ll}
\hline Complex & $\Delta \mathbf{G} / \mathbf{k J ~ m o l}^{-1}$ \\
\hline $\mathrm{I}-\mathrm{Cl}$ & 3.58 \\
$\mathrm{II}-\mathrm{Cl}$ & -82.5 \\
$\mathrm{III}-\mathrm{Cl}$ & 0.00 \\
\hline
\end{tabular}


Table S8. Relative free energies of the $\mathrm{Rh}$ complexes with $\mathrm{BF}_{4}$ present for the proposed mechanism butene isomerization.

\begin{tabular}{ll}
\hline Complex & $\Delta \mathbf{G} / \mathbf{k J ~ m o l}^{-1}$ \\
\hline $\mathrm{I}-\mathrm{BF}_{4}$ & -1.08 \\
$\mathrm{II}-\mathrm{BF}_{4}$ & -32.2 \\
$\mathrm{III}-\mathrm{BF}_{4}$ & 0.00 \\
\hline
\end{tabular}

Table S9. Simulated surface areas (SA) and probe occupiable pore volumes (PV).

\begin{tabular}{|c|c|c|}
\hline Sample & $S A / m^{2} g^{-1}$ & $\mathrm{PV} / \mathrm{m}^{3} \mathrm{~g}^{-1}$ \\
\hline 1.ETH-BF 4 (disorder 1) & 973 & 0.30 \\
\hline 1. $\mathrm{ETH}^{-\mathrm{BF}_{4}}$ (disorder 2) & 913 & 0.28 \\
\hline 1·ETH-Cl (disorder 1) & 893 & 0.29 \\
\hline 1.ETH-Cl (disorder 2) & 867 & 0.29 \\
\hline 1.NBD-BF 4 (disorder 1) & 989 & 0.29 \\
\hline 1.NDB-BF 4 (disorder 2) & 989 & 0.29 \\
\hline 1.NBD-Cl (disorder 1) & 871 & 0.27 \\
\hline 1.NBD-Cl (disorder 2) & 850 & 0.26 \\
\hline
\end{tabular}




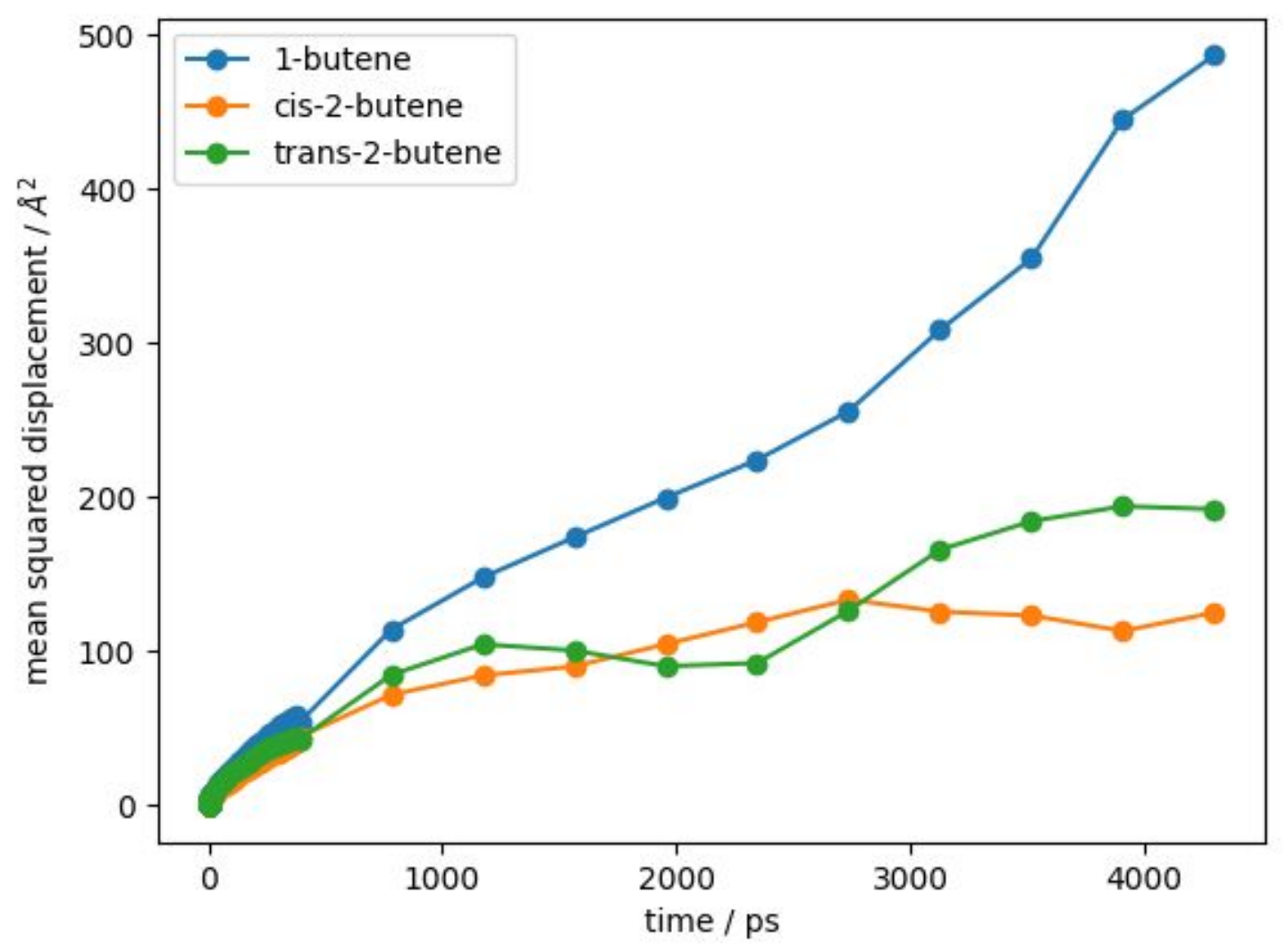

Figure SI 11.2: Mean squared displacement of butane species at $300 \mathrm{~K}$ using the NVT ensemble within the rigid structure of $1 \cdot \mathrm{ETH}_{-}-\mathrm{BF}_{4}$. 


\section{SI 11.1 DFT Calculations on butene transport within 1-ETH-X}

\section{SI 11.1.1 Computational details}

Despite the above technological methods, first principles were employed to reveal the catalytic enhancement mechanism of 1-butene isomerization. All the simulations were carried out using density functional theory (DFT) on the Vienna Ab initio Simulation Package (VASP). ${ }^{12-13}$ The interaction between ions and electrons was described by projector-augmented wave (PAW) method. The electron exchangecorrelation energy is performed using generalized gradient approximation functional with the PerdewBurke-Ernzerh correction. ${ }^{14}$ The energy-cutoffs for all systems were set to be $400 \mathrm{eV}$. The whole model for the Rh/Mn MOF contains 372 atoms. The criteria for the relaxation of the electronic SC-loop was set to be $1 \times 10^{-6} \mathrm{eV} \AA^{-1}$. And the relaxation will be stopped after the convergence of forces reached $0.03 \mathrm{eV}$ $\AA^{-1}$. The $k$-points grid was set as $(1 \times 1 \times 1)$ and generated with Gamma centered points. During the geometry optimization, the ions in reactants, intermediates and products were fully relaxed. The transition states were located by climbing images nudged elastic band $(\mathrm{Cl}-\mathrm{NEB})^{15-16}$ and dimmer methods. ${ }^{17}$

\section{SI 11.1.2 Results and discussion}

DFT calculations were carried out to gain deep insight into the catalytic action of MOFs in the isomerization of 1-butene. Fig. 1 illustrates the potential energy surfaces (PESs) of 1-butene isomerization with and without the presence of MOFs. The bond lengths as well as atom numbers are labeled in blue. Direct isomerization of 1-butene proceeds with $\mathrm{H} 4$ atom migrating from C3 atom to $\mathrm{C} 1$ atom (TS1 in Fig. 1), but the energy barrier for the formation of 2-butene is as high as $2.96 \mathrm{eV}$, indicating a low feasibility of this process.

When the MOF structure exists, the process is significantly promoted. To deeply investigate the enhancement caused by Rh sites, Bader charges of active sites are analyzed. In the MOF, each fluorine ion is negatively charged by $\sim 0.83$ electron, each boron ion has 2.36 positive charge, hence the [BF4] group has 0.96 negative charge. In this paper, the [BF4] anion will not participate in the1-butene isomerization directly according to the special structure of MOF. Instead, the interaction between $\mathrm{Rh}$ and $\mathrm{C}=\mathrm{C}$ double bonds play a dominant role.

As shown in blue lines in Fig. 1, the isomerization of 1-butene is divided into three elementary reactions including conformation isomerization and two steps of hydrogen migration. Analysis of the differential charge density of IM1 (Fig. 2) shows that the $\pi$ electrons from $\mathrm{C}=\mathrm{C}$ double bonds exhibit a strong interaction with the $\mathrm{d}$ orbitals of $\mathrm{Rh}$ site, and the valence electrons of $\mathrm{Rh}$ somehow donate to the electron densities around $\mathrm{C} 1$ and $\mathrm{C} 2$, as observed by Douglas et al. ${ }^{18}$ Then the conformation IM1 endothermically isomerizes to IM2 with the $\mathrm{C} 3-\mathrm{H} 4$ bond lengthened by $0.10 \AA$. . As shown in Fig. 2, electron densities are mainly distributed between $\mathrm{Rh}$ and $\mathrm{C} 1 / \mathrm{C} 2 / \mathrm{C} 3$, which means that the $\pi$ electrons are delocalized from $\mathrm{C} 1 / \mathrm{C} 2$ to $\mathrm{C} 1 / \mathrm{C} 2 / \mathrm{C} 3$. The dehydrogenation of 1-butene (IM2 $\rightarrow \mathrm{TS} 2$ ) takes place with a moderate energy barrier of $0.31 \mathrm{eV}$, and IM3 is formed after the $\mathrm{H} 4$ atom migrating to Rh. The significantly reduced energy barrier is ascribed to the reduced electrophilicity of C3 atom which causes bond energy of C3-H4 decrease, and hence the cleavage of $\mathrm{C} 3-\mathrm{H} 4$ bond becomes easier. The Bader charge analysis also shows few electrons are transferred from $\mathrm{H} 4$ to $\mathrm{C} 3$. 
In IM3, the Rh site loses more electrons, and the $\mathrm{Rh}-\mathrm{H}$ bonds is unstable especially with the presence of delocalized $\pi$ electrons. Hence, the negatively charged $\mathrm{H} 4$ atom is reactive to associated with $\mathrm{C} 1$ to stabilize the system. Compared to re-isomerize back to $\mathrm{C} 3$ atom, $\mathrm{H} 4$ favors to transfer to $\mathrm{C} 1$ atom (IM3 $\rightarrow$ IM4) because of high thermodynamic feasibility. The formation of IM4 owns a moderate energy barrier of $0.17 \mathrm{eV}$ and is exothermic by releasing energy of $0.88 \mathrm{eV}$. This process is driven by the symmetry effect. When $\mathrm{H} 4$ transfers to $\mathrm{C} 1,2$-butene is produced with high symmetry. The charges of C2 and C3 are similar. The differential charge density of IM4 also shows a symmetrically contribution of the molecules. Along the total pathways of 1-butene (from IM1 to IM4), we can conclude that the H4 migration to the Rh site is rate-determining step as it occupies the top position in the PES file.

To conclude, the DFT simulation reveals the interaction between $\pi$ electrons and $d$ orbitals of active Rh site of MOF has a significant enhancement of the 1-butene isomerization by reducing the energy barrier from $2.96 \mathrm{eV}$ to $0.68 \mathrm{eV}$ in the PES. Hydrogen migration from $\alpha-\mathrm{C}$ (C3) to Rh site is the rate determining step.

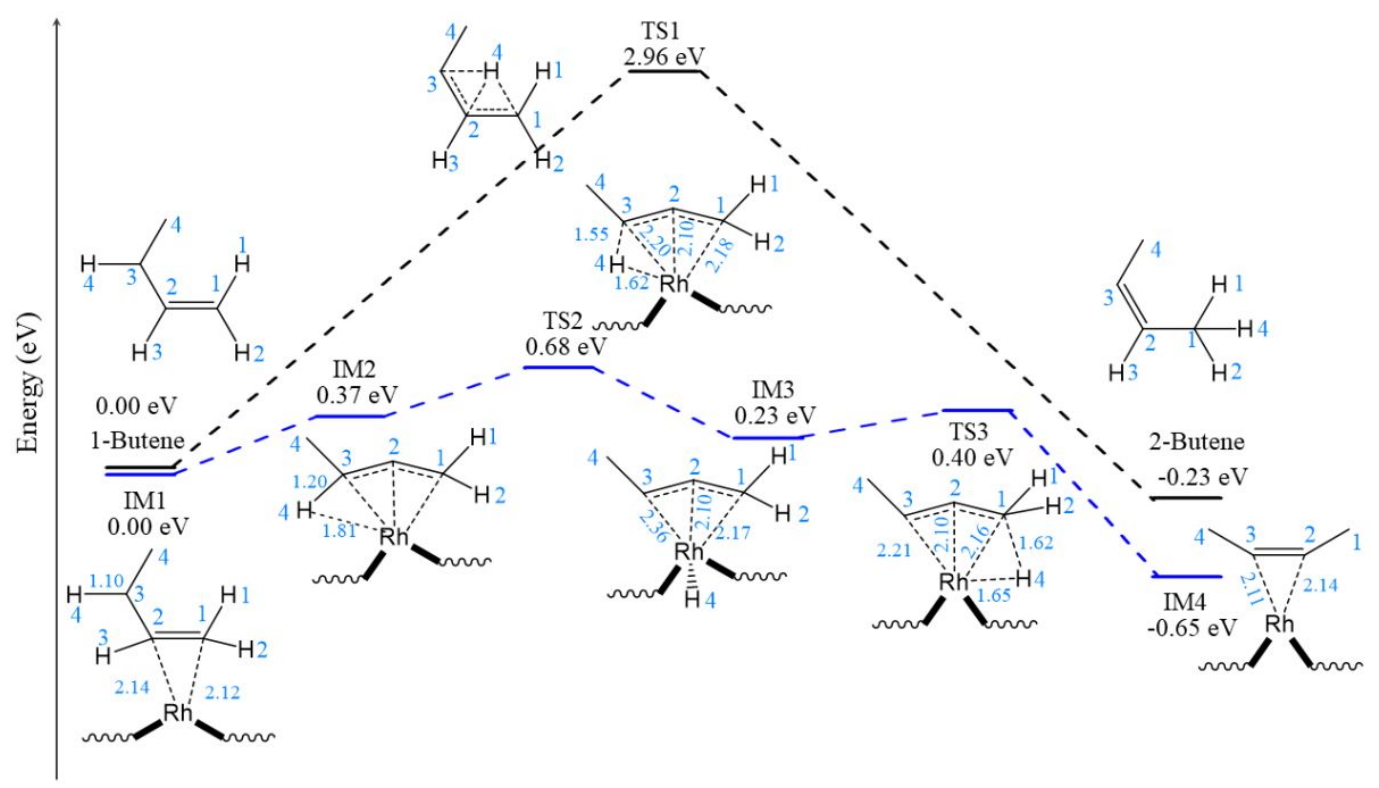

Fig. SI 11.1.1: Potential energy surfaces of 1-butene isomerization in the absence (black line) and presence (blue line) of MOF. Bond lengths and atom numbers are labelled in blue. 
Table S10. Bader charge of active sites in the intermediates and transition states.

\begin{tabular}{lllllll}
\hline & $\mathrm{IM} 1$ & $\mathrm{IM} 2$ & $\mathrm{TS} 2$ & $\mathrm{IM} 3$ & $\mathrm{TS} 3$ & $\mathrm{IM} 4$ \\
\hline $\mathrm{C} 1$ & -0.227 & -0.226 & -0.220 & -0.223 & -0.224 & -0.150 \\
$\mathrm{C} 2$ & -0.193 & -0.172 & -0.197 & -0.155 & -0.087 & -0.103 \\
$\mathrm{C} 3$ & -0.092 & -0.076 & -0.150 & -0.097 & -0.200 & -0.113 \\
$\mathrm{H} 4$ & 0.033 & 0.009 & 0.059 & -0.038 & 0.053 & 0.092 \\
Rh & 0.410 & 0.436 & 0.464 & 0.531 & 0.478 & 0.363 \\
\hline
\end{tabular}

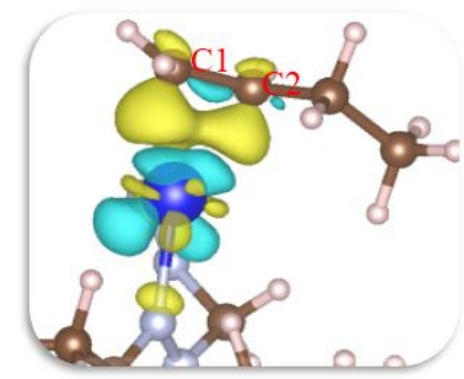

IM1

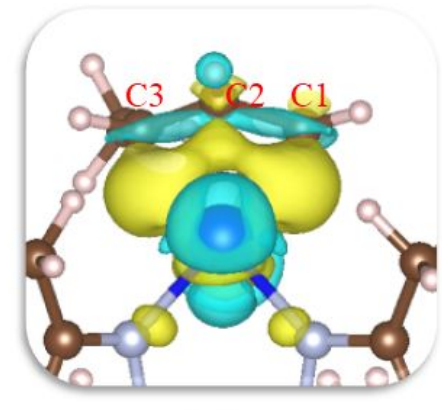

IM3

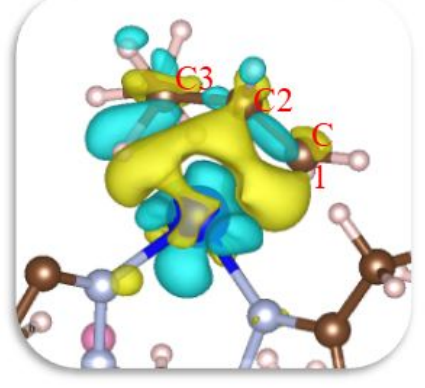

IM2

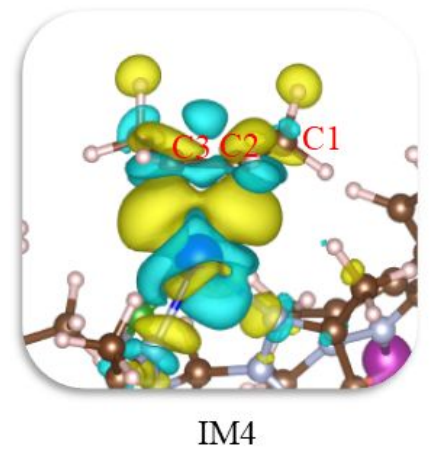

IM4

Fig. SI 11.1.2: Differential charge density of intermediates referred in the MOF-promoted 1-butene isomerization. Blue surface designates the charge density reduced area, and the yellow surface represents the charge density increased area. 


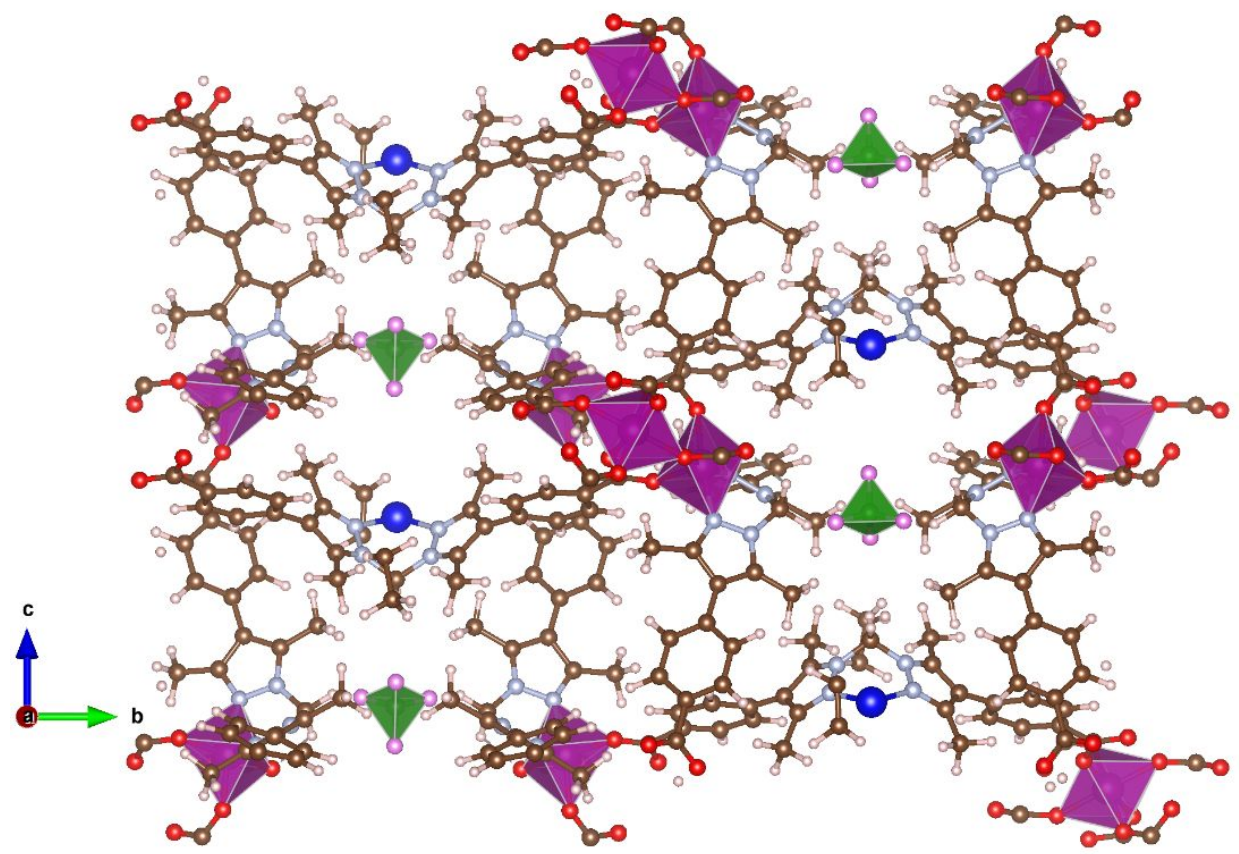

Fig. SI 11.1.3: Periodical structure $(1 \times 1 \times 2)$ of MOF used in the DFT simulation. The atoms are colored by $\mathrm{H}$ in white, $\mathrm{B}$ in green, $\mathrm{C}$ in brown, $\mathrm{N}$ in silvery white, $\mathrm{O}$ in red, $\mathrm{F}$ in pink, $\mathrm{Mn}$ in purple and $\mathrm{Rh}$ in blue. 


\section{SI 12.0 References}

(1) Cowieson, N. P.; Aragao, D.; Clift, M.; Ericsson, D. J.; Gee, C.; Harrop, S. J.; Mudie, N.; Panjikar, S.; Price, J. R.; Riboldi-Tunnicliffe, A.; Williamson, R.; Caradoc-Davies, T. MX1: a bending-magnet crystallography beamline serving both chemical and macromolecular crystallography communities at the Australian Synchrotron. J. Synchrotron Radiat. 2015, 22, 187.

(2) McPhillips, T.; McPhillips, S.; Chiu, H.; Cohen, A. E.; Deacon, A. M.; Ellis, P. J.; Garman, E.; Gonzalez, A.; Sauter, N. K.; Phizackerley, R. P.; Soltis, S. M.; Kuhn, P. Blue-Ice and the Distributed Control System software for data acquisition and instrument control at macromolecular crystallography beamlines. J. Synchrotron Radiat. 2002, 9, 401.

(3) Sheldrick, G. A short history of SHELX. Acta. Crystallogr. A 2008, 64, 112.

(4) Sheldrick, G. SHELXT - Integrated space-group and crystal-structure determination. Acta. Crystallogr. A 2015, 71, 3.

(5) Sheldrick, G. M. Crystal structure refinement with SHELXL. Acta. Crystallogr. C 2015, 71, 3.

(6) Barbour, L. J. X-Seed - A Software Tool for Supramolecular Crystallography. J. Supramol. Chem. 2001, 1, 189.

(7) Dolomanov, O. V.; Bourhis, L. J.; Gildea, R. J.; Howard, J. A. K.; Puschmann, H. OLEX2: a complete structure solution, refinement and analysis program. J. Appl. Crystallogr. 2009, 42, 339.

(8) Spek, A. L. PLATON SQUEEZE: a tool for the calculation of the disordered solvent contribution to the calculated structure factors. Acta. Crystallogr. C 2015, 71, 9.

(9) Erdogan, G.; Grotjahn, D. B. Mild and Selective Deuteration and Isomerization of Alkenes by a Bifunctional Catalyst and Deuterium Oxide. J. Am. Chem. Soc. 2009, 131, 10354.

(10) Pike, S. D.; Krämer, T.; Rees, N. H.; Macgregor, S. A.; Weller, A. S. Stoichiometric and Catalytic SolidGas Reactivity of Rhodium Bis-phosphine Complexes. Organometallics 2015, 34, 1487.

(11) Chadwick, F. M.; McKay, A. I.; Martinez-Martinez, A. J.; Rees, N. H.; Kramer, T.; Macgregor, S. A.; Weller, A. S. Solid-state molecular organometallic chemistry. Single-crystal to single-crystal reactivity and catalysis with light hydrocarbon substrates. Chem. Sci. 2017, 8, 6014.

(12) Hafner, J. Ab-initio simulations of materials using VASP: Density-functional theory and beyond. J. Comput. Chem. 2008, 29, 2044.

(13) Kresse, G.; Furthmüller, J. Efficient iterative schemes for ab initio total-energy calculations using a plane-wave basis set. Phys. Rev. B 1996, 54, 11169.

(14) Perdew, J. P.; Burke, K.; Ernzerhof, M. Generalized Gradient Approximation Made Simple. Phys. Rev. Lett. 1996, 77, 3865.

(15) Henkelman, G.; Uberuaga, B. P.; Jónsson, H. A climbing image nudged elastic band method for finding saddle points and minimum energy paths. J. Chem. Phys. 2000, 113, 9901.

(16) Henkelman, G.; Jónsson, H. Improved tangent estimate in the nudged elastic band method for finding minimum energy paths and saddle points. J. Chem. Phys. 2000, 113, 9978.

(17) Xiao, P.; Sheppard, D.; Rogal, J.; Henkelman, G. Solid-state dimer method for calculating solid-solid phase transitions. J. Chem. Phys. 2014, 140, 174104.

(18) Douglas, T. M.; Brayshaw, S. K.; Dallanegra, R.; Kociok-Köhn, G.; Macgregor, S. A.; Moxham, G. L.; Weller, A. S.; Wondimagegn, T.; Vadivelu, P. Intramolecular Alkyl Phosphine Dehydrogenation in Cationic Rhodium Complexes of Tris(cyclopentylphosphine). Chem. Eur. J. 2008, 14, 1004. 